\title{
Effect of microstructure on early oxidation of MCrAIY coatings
}

DOI:

10.1016/j.actamat.2018.08.018

\section{Document Version}

Accepted author manuscript

Link to publication record in Manchester Research Explorer

\section{Citation for published version (APA):}

Chen, Y., Zhao, X., \& Xiao, P. (2018). Effect of microstructure on early oxidation of MCrAlY coatings. Acta Materialia, 159, 150-162. https://doi.org/10.1016/j.actamat.2018.08.018

\section{Published in:}

Acta Materialia

\section{Citing this paper}

Please note that where the full-text provided on Manchester Research Explorer is the Author Accepted Manuscript or Proof version this may differ from the final Published version. If citing, it is advised that you check and use the publisher's definitive version.

\section{General rights}

Copyright and moral rights for the publications made accessible in the Research Explorer are retained by the authors and/or other copyright owners and it is a condition of accessing publications that users recognise and abide by the legal requirements associated with these rights.

\section{Takedown policy}

If you believe that this document breaches copyright please refer to the University of Manchester's Takedown Procedures [http://man.ac.uk/04Y6Bo] or contact uml.scholarlycommunications@manchester.ac.uk providing relevant details, so we can investigate your claim.

\section{OPEN ACCESS}


Materialia

Elsevier Editorial system(tm) for Acta

Manuscript Draft

Manuscript Number: A-18-1526R1

Title: Effect of microstructure on early oxidation of MCrAly coatings

Article Type: Full length article

Keywords: MCrAlY; Oxidation; Microstructure

Corresponding Author: Professor Ping Xiao, PhD

Corresponding Author's Institution: University of Manchester

First Author: Ying Chen, PhD

Order of Authors: Ying Chen, PhD; Xiaofeng Zhao, PhD; Ping Xiao, PhD

Abstract: Two MCrAlY coatings with the same nominal composition, but different microstructures are deposited onto Hastelloy ${ }^{\circledR} \mathrm{X}$ superalloy substrates by low pressure plasma spraying (LPPS) and high velocity oxygen fuel (HVOF) spraying, respectively. The early oxidation behaviour of the coatings at $1150{ }^{\circ} \mathrm{C}$ is studied. For the LPPS coating with relative coarse grains, the $\gamma$ and $\beta$-phase show different oxidation behaviours: the oxide on the $Y$ phase shows a multi-layer structure, consisting of outer $(\mathrm{Ni}, \mathrm{Co})(\mathrm{Cr}, \mathrm{Al}) 204$, intermediate (Cr, Al) 203 and inner $\alpha-\mathrm{Al} 203$; the oxidation of the $\beta$-phase, however, is characterised by selective oxidation of aluminium and the oxide is composed of a mixture of $\theta$ and $\alpha-$ Al203. For the nanocrystalline HVOF coating, it does not show sitespecific oxidation and the oxidation is characterised by formation of an exclusive $\alpha$-Al203 scale over the surface. The microstructure-dependent oxidation is quantitatively described from the perspective of oxidation kinetics, with contribution from both lattice and grain boundary diffusion taken into consideration. A critical grain size of the $Y$ phase, below which formation of an exclusive Al203 scale can be achieved, is predicted and verified. The study gives new insights into oxidation of MCrAlY coatings. 
School of Materials University of Manchester

Manchester M13 9PL

Tel: $44-1613065941$

Fax: 44-161306 3586

Email: ping.xiao@manchester.ac.uk

Ref.: Ms. No. A-18-1526

Effect of microstructure on early oxidation of MCrAlY coatings Acta Materialia Dear Professor Nitin Padture,

Thanks for your efforts to arrange the review of the manuscript and we appreciate the valuable comments given by the reviewers. In this version, we have addressed all of the comments (please see the "responses to reviewers" letter for details) and revisions have been made accordingly (highlighted by red in the revised manuscript). I wish that the revisions are satisfactory for publication of the paper. Please let us know if we need to make more effort in improvement of this paper.

Yours sincerely,

Ying Chen and Ping Xiao 


\section{Response to Reviewers}

\section{Reviewer \#1: Review of Acta Met A-18-1525 Effect of microstructure on early oxidation of MCrAlY coatings by Ying Chen et al.}

This paper describes the early oxidation of both an LPPS and HVOF bond coat. The materials is excellently presented in nearly flawless English. In the end the rapid transport of Aluminum by grain boundaries explains nearly all the is observed. Much background is already known and well review in the paper. The paper does an excellent job of putting all the pieces together and extensive experimental results are shown including PLPS (oxide too thin for XRD) SEM and TEM using multiple techniques in the TEM. They then model the results to explain in a semi quantitative way why the results are the way they are. Generally a very nice paper. This reviewer enjoyed reading this well written paper. One caveat is that this reviewer although very familiar with the results in this filed is not an expert on which exact references are most appropriate. The following things can be improved.

1. For less experienced readers they should give the composition and crystal structure of gamma and beta phases.

Reply: We have added a table (Table 2) listing the compositions of the $\beta$ and $y$-phase determined by energy dispersive $X$-ray spectroscopy (see Table 2 and corresponding text in Line 11-12, Page 5) The crystal structures of the $Y$ and $\beta$-phases are given in Introduction (Line 8-9, Page 2).

2. On page 12 they state that equilibrium imposes strict restrictions on the multi-phase alloy. True but how does this play into the discussed behavior.

Reply: This statement is to stress that the thermodynamic equilibrium in the two-phase NiCoCrAlY coating prevents the interaction of $J_{A l}^{\gamma} J_{A l}^{\beta}$ and $J_{A l}^{G B}$ in the alloy.

We have added this point into the text (Line 7-8, Page 13)

3.p. 3 the bond coats were over 200 microns thick. Probably not important given the short heating but typical bond coats are much thinner. If there is a reason for this choice it is worth stating.

Reply: The reason for using a relatively thick coating is to eliminate the effect of substrate/coating interfusion on the early oxidation of the coatings.

This statement has been added into the text (Line 41-43, Page 3)

4.P.4 It says the samples were heated to $1150 \mathrm{C}$ at $200 \mathrm{C} /$ minute and air cooling. At this rate could be a question of will the samples heat fast enough to follow the furnace temperature setting and the question of how fast the 
early cooling was. A bit more detail is needed to justify that this heating was achieved in the time specified. Ideally a welded thermocouple on the back of the sample could have proved this.

Reply: The furnace we used for the oxidation experiment had a thermocouple fitted in the centre of the heating chamber and the samples were placed next to the thermocouple. The thermocouple monitored the temperatures around the samples and synchronises the temperature data to the control program, which constantly adjust the input power to meet the temperature setting.

The above description has been added into the text (Line 15-19, Page 4).

5. On page line 21 it talks about the buried alpha compensating for the different fluoresce flux by the over lying other oxide. Since the sensitivity ratio is 10 . Seems this should be stated as possibly helping but not glossed over like it would somehow luckily attenuate the correct large amount. It seems unlikely that the thin over layer can give $10 \mathrm{X}$ attenuation. This should be more honestly admitted. Such an admission would not seem to undermine any of the main arguments.

Reply: We have added a statement to admit the thin top $\theta-\mathrm{Al}_{2} \mathrm{O}_{3}$ layer is unlike to fully compensate the difference in luminescence intensity between the $\theta-\mathrm{Al}_{2} \mathrm{O}_{3}$ and $a-\mathrm{Al}_{2} \mathrm{O}_{3}$. Please see line 28-30, Page 6.

6.page 9 line 22 statement should be clearer. What they are saying is that for continuous Alpha formation that the current aluminum replacement needs to be sufficient or more than sufficient to compensate the loss by alumina formation. There is no reason to assume that this is always at the minimum.

Reply: The statement has been revised (Line 28-29, Page 9)

7.page 7 they say the formation of theta is 10 times faster than the formation of alpha. Based on what? The measured thicknesses or some reference? Justify the comment.

Reply: The statement is based on the references 37 and 38 cited in the text (Line 40, Page 7).

8.page 13, they apparently look at a grain of $700 \mathrm{~nm}$ such that the alpha alumina forms on the beta and claim that 700 or smaller is needed. However this is a case where the alpha alumina formed. How do they know it would not also form at $900 \mathrm{~nm}$. Seems this is really a lower bound to the upper limit. This needs to be explained what the thinking is here or this admitted as a bound.

Reply: We have added a short explanation of this critical grain size and admitted that it could span a certain range (Line 34-41, Page 13)

9.Two corrections of English, on Page 13 line 10 and on page 4 Line 24 in both places the word details is used when the word detail should be used. 
Very minor but should be corrected to go with the rest of the perfect English used.

Reply: We have replaced the original words with more detailed words. Please see line 27, Page 4 and Line 21, Page 13.

Two auxiliary comments for their consideration.

1.One of the TEM images (b) marks y rich precipitates. They might note that these are oxygen diffusion paths which if spanning the oxide short circuit the alumina as a diffusion barrier and have cause poor BC performance in some cases.

Reply: At this stage it is difficult to know if the Y-rich precipitates will span the $\mathrm{Al}_{2} \mathrm{O}_{3}$ layer and how they will affect the performance of the bond coat in long term service based on the early oxidation experiments conducted in this work. We will bear this comment in mind in our future work.

2.The discussion notes that deformation related defects help alpha alumina formation. There is growing evidence that HVAF bond coats outperform even HVOF. HVAV results in even more plastic deformation so the HVAF results can be explained by what they are saying and it may be worth adding this point.

Reply: We have added this point into the text (Line 7-10, Page 15).

In summary a very good paper. The most important things to change are in comments 8 and 5 . This paper should be easily improved as indicated above and published.

\section{Reviewer \#2}

Authors have conducted high temperature oxidation behavior at the very early stage focused on microstructures for two different spray processes used MCrAlY coatings.

This article is very important and interesting for understanding fundamental on initial stage of high temperature oxidation of MCrAlYs. However, some revisions are necessary before paper acceptance.

1. Authors applied 1150 deg.C for the high temperature oxidation tests. But in the case of blades of gas turbines or aerospace engines, surface temperature is approximately $900-1000$ deg.C. Why authors did choose this temperature?

Reply: Oxidation of MCrAIY at a relatively low temperature (e.g. 900$1000^{\circ} \mathrm{C}$ ) is significantly slower than that at $1150^{\circ} \mathrm{C}$ and a short period of oxidation (e.g. 5 minutes) at $900-1000{ }^{\circ} \mathrm{C}$ would produce an 
extremely thin oxide layer, which makes it extremely difficult to characterise and analyse. The model study in this work used a slightly higher temperature to avoid this problem, but could still capture the physical essence and provide mechanistic understanding of the early oxidation of the MCrAlY coatings.

On the other hand, it is expected that gas-turbine engine will run at even higher temperatures in future. The study in this work could be also helpful to understanding the early oxidation behaviour of MCrAlY coatings at such temperatures.

2. After "2. Materials and Methods", authors should use "NiCoCrAlY" instead of MCrAIY.

Reply: "MCrAlY" has been replaced by "NiCoCrAlY" throughout the text after "2. Materials and Methods".

3. P.3, L.7: Al2O3 --> "l" is subscript notation. Please correct it.

Reply: The above typo has been corrected (Line 7, Page 3)

4. Authors applied annealing treatment at 1100 deg.C for $2 \mathrm{~h}$ under $10-5 \mathrm{mbar}$ environment for only LPPS coating. Please explain the reason why.

Reply: The reason that post-deposition annealing was applied to LPPS, but not HVOF, was to avoid undesirable grain growth of the nanocrystalline HVOF coating. As the focus of this study is the effect of microstructure on oxidation of the MCrAlY coating, creating two distinct microstructures is essential to our study.

This explanation has been added into the text (Line 3, Page 4).

5. Authors used several symbols in section 4. It is better to write up used symbols as "nomenclature".

Reply: A nomenclature has been added into the revised manuscript.

6. P.10, L.26: Authors mentioned "EBSD analysis also shows that the grain boundaries are predominately high-angle grain boundaries and on average a gamma-grain is bordered by five beta-grains and one gamma-grain." How did authors find the five beta-grains and one gamma-grain?

Reply: This finding is determined by image analysis of the EBSD phasecontrast maps ( 3 in total) of the LPPS coating, in which the contours of over $50 y$-grains and their surrounding grains are analysed.

A short description of these details has been added into line 31, Page 10 and line 1, Page 11.

7. P.12, L.6: Authors assigned four different sets of values. How did authors choose these values? 
Reply: These values are assigned based on the assumption that the grain boundary diffusion is orders of magnitude faster than lattice diffusion. We believe that the values are qualitatively reasonable, although it is currently not possible to justify these values quantitatively as the lattice and grain boundary diffusion coefficients of aluminium in the NiCoCrAlY bond coat at $1150^{\circ} \mathrm{C}$ are not available in the literature. Nevertheless, these values are selected only to provide some examples on how the fast grain boundary diffusion of $\mathrm{Al}$ in the coating could affect the selective oxidation of aluminium as a function of grain size.

8. P.15, L.15, Section 4.4: There is no image, no information about microstructure and coating process. And I felt this section is digression. Please consider whether this section is necessary or not.

Reply: We think this section is an extension of our study on MCrAlY coatings and is helpful to understanding the oxidation of the Ptdiffused $Y / Y^{\prime}$ bond coat. We have added an EBSD image (Fig.13), which shows the nanostructured grains in the surface region of a Ptdiffused $Y / Y^{\prime}$ bond coat, to strength our discussion in this section.

A short description of Fig.13 is also added into the text (Line 13-15, Page 16)

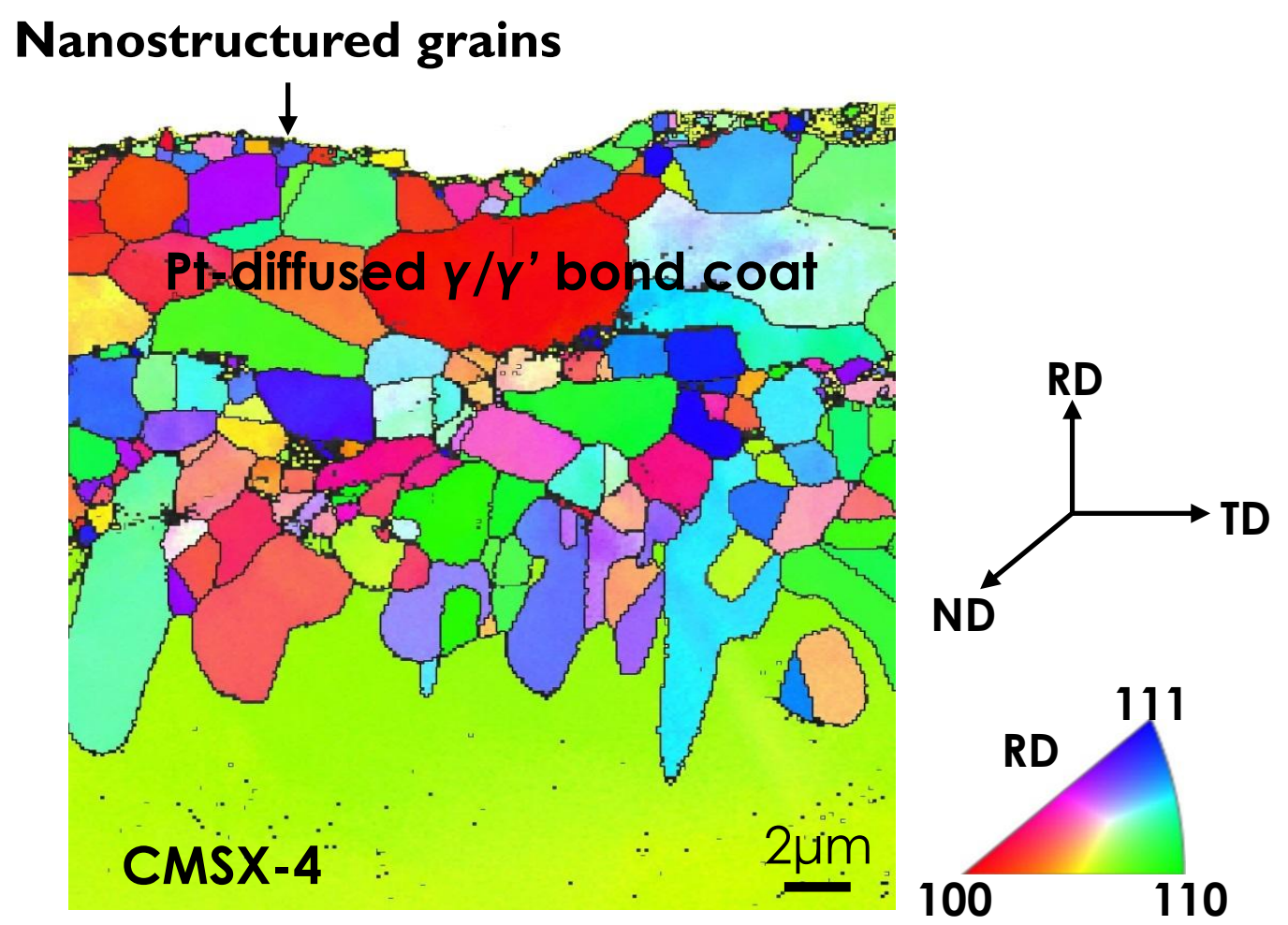

Fig.13. Cross-sectional EBSD inverse pole figure map (RD) of an asdeposited Pt-diffused $Y / Y^{\prime}$ coating showing the nanostructured grains in the surface region 
1

\title{
Effect of microstructure on early oxidation of MCrAlY coatings
}

\author{
Ying Chen', Xiaofeng Zhao² and Ping Xiao', $2 \dagger$ \\ 1 School of Materials, University of Manchester, Manchester, M13 9PL, UK \\ 2 Shanghai Key Laboratory of Advanced High-Temperature Materials and \\ Precision Forming, Shanghai Jiao Tong University, Shanghai, 200240, PR China
}

\section{Abstract}

Two MCrAIY coatings with the same nominal composition, but different microstructures are deposited onto Hastelloy ${ }^{\circledR} X$ superalloy substrates by low-pressure plasma spraying (LPPS) and high velocity oxygen fuel (HVOF) spraying, respectively. The early oxidation behaviour of the coatings at $1150^{\circ} \mathrm{C}$ is studied. For the LPPS coating with relative coarse grains, the $y$ and $\beta$-phase show different oxidation behaviours: the oxide on the $y$-phase shows a multi-layer structure, consisting of outer $(\mathrm{Ni}, \mathrm{CO})(\mathrm{Cr}, \mathrm{Al})_{2} \mathrm{O}_{4}$, intermediate $(\mathrm{Cr}, \mathrm{Al})_{2} \mathrm{O}_{3}$ and inner $\mathrm{a}-\mathrm{Al}_{2} \mathrm{O}_{3}$; the oxidation of the $\beta$-phase, however, is characterised by selective oxidation of aluminium and the oxide is composed of a mixture of $\theta$ and $a-\mathrm{Al}_{2} \mathrm{O}_{3}$. For the nanocrystalline HVOF coating, it does not show site-specific oxidation and the oxidation is characterised by formation of an exclusive $a-\mathrm{Al}_{2} \mathrm{O}_{3}$ scale over the surface. The microstructure-dependent oxidation is quantitatively described from the perspective of oxidation kinetics, with contribution from both lattice and grain boundary diffusion taken into consideration. A critical grain size of the $y$-phase, below which formation of an exclusive $\mathrm{Al}_{2} \mathrm{O}_{3}$ scale can be achieved, is predicted and verified. The study gives new insights into oxidation of MCrAlY coatings.

Keywords: MCrAlY; Oxidation; Microstructure

\section{Introduction}

MCrAIY (M=Ni, Co or a mixture of the two) overlay coatings are widely applied to thermally loaded structures (e.g. gas-turbine blades made of Ni-base superalloys) to protect the components against oxidation and corrosion during service at high temperature [1-4]. The oxidation resistance of these coatings is mainly determined by their chemical compositions, which are carefully engineered to achieve high melting points and capabilities to develop a thermodynamically stable, slow growing, adherent and mechanically robust a- $\mathrm{Al}_{2} \mathrm{O}_{3}$ scale over the coating surface upon exposure to high temperatures. The formation of the protective $a-\mathrm{Al}_{2} \mathrm{O}_{3}$ scale becomes

${ }^{\dagger}$ Corresponding author: Ping Xiao (p.xiao@manchester.ac.uk). 
even more essential when a thermal barrier coating (TBC, typically made of 7-8 wt\% yttria stabilised zirconia (YSZ)) is applied on top of the MCrAlY coating, because $a-\mathrm{Al}_{2} \mathrm{O}_{3}$ is not only an efficient oxygen diffusion barrier, but also thermodynamically compatible with the YSZ TBC (e.g. they do not form interphases and their mutual solubility is very limited) [5], which is critical to the maintenance of the interfacial adhesion upon thermal exposure.

Typical MCrAlY coatings show a two-phase structure: a brittle, Al-rich $\beta$-phase ( $\mathrm{Cs} C \mathrm{Cl}$ structure) embedded in a ductile, Al-poor $\mathrm{Y}$-phase matrix (face centred cubic structure). The application of this two-phase structure is to achieve a balance between oxidation resistance and mechanical properties: the $\beta$ phase acts as an aluminium reservoir and offers oxidation resistance; the $Y$ phase improves ductility, thereby reducing the susceptibility of the coatings to brittle cracking induced by thermos-mechanical fatigue [6]. Oxidation of MCrAlY coatings has been extensively studied, and these studies have provided considerable insights into the underlying oxidation mechanisms. However, substantial variations in oxidation kinetics (e.g. whether the growth of the oxide follows a parabolic or subparabolic law [7-10]) and oxide compositions (e.g. whether the oxide scale is composed of predominately $\mathrm{Al}_{2} \mathrm{O}_{3}$ or a mixture of $\mathrm{Al}_{2} \mathrm{O}_{3}$ and $\mathrm{Ni} / \mathrm{Co} / \mathrm{Cr}$ - rich oxides [11-13]) have been reported. These discrepancies could be partially explained by the variations in oxidation conditions (e.g. temperatures, environmental oxygen partial pressures [7, 14, 15]), geometrical factors (e.g. surface roughness [16]) and the coating compositions, especially the content of reactive element (e.g. yttrium [8, 17]). However, the facts that for a given oxidation condition MCrAlY coatings with the same composition but different microstructures could differ substantially in oxidation behaviour suggest that composition and oxidation condition alone do not compose the full story [11, 12, 18]. A further complication concerning the oxidation behaviour of the MCrAlY coatings is that the coating has a two-phase structure, in which the individual phase could show different oxidation behaviours, at least during initial stage of the oxidation $[11,19,20]$.

It is widely accepted that between $750-1200^{\circ} \mathrm{C}$ the growth of a- $\mathrm{Al}_{2} \mathrm{O}_{3}$ scales is controlled by the concurrent, counter-diffusion of anions ( $\left.\mathrm{O}^{2-}\right)$ and cations $\left(\mathrm{Al}^{3+}\right)$ along the grain boundaries of the growing oxide [21, 22]. However, the formation of such a continuous, protective $a-\mathrm{Al}_{2} \mathrm{O}_{3}$ scale is generally preceded by an initially fast oxidation stage associated with severe Al depletion and subsequent formation of the "non-protective" oxides such as $\mathrm{NiO},(\mathrm{Ni}, \mathrm{Co})(\mathrm{Cr}, \mathrm{Al})_{2} \mathrm{O}_{4}$, and $\mathrm{Cr}_{2} \mathrm{O}_{3}$. [1 1, 23-28]. The formation of these fast growing, brittle transient oxides is undesirable as they reduce the protectiveness of the scales and undermine the interfacial adhesion [5], especially in the case when YSZ TBCs are applied. During the transient oxidation stage when the multi-component MCrAlY alloy surface is fully exposed to the atmosphere, the resulting oxide composition and microstructure depend on the supply of the metal elements to the surface according to the Wagner's oxidation theory $[29,30]$. The diffusion fluxes of the 
1 alloy elements towards the surface, in turn, are not only determined by the

2 composition, but also the microstructure of the underlying metal [31] (e.g. the number of crystallographic defects, such as grain boundaries, which are fast diffusion paths). On the other hand, even under the circumstances when growth of $\mathrm{Al}_{2} \mathrm{O}_{3}$ is kinetically favoured during the transient oxidation stage, formation of the protective $a-\mathrm{Al}_{2} \mathrm{O}_{3}$ is often accompanied with nucleation and growth of metastable $\mathrm{A}_{2} \mathrm{O}_{3}$ polymorphs (e.g. $\theta-\mathrm{Al}_{2} \mathrm{O}_{3}$ ) $[10,32,33]$. The metastable $\mathrm{Al}_{2} \mathrm{O}_{3}$ is less protective, and undergoes a progressive phase transformation to $a-\mathrm{Al}_{2} \mathrm{O}_{3}$ during the subsequent oxidation process. This phase transformation causes a disruptive volume shrinkage and tensile stress in the scale, which could compromise the structural integrity of the scale [32]. Nevertheless, the transient oxidation of MCrAlY coatings, especially at the very early stage of the oxidation, has yet to be sufficiently characterised or understood, not to mention a thorough understanding of the relationship between the oxide composition and the underlying coating alloy microstructure.

The objective of this study is to provide detailed characterisation and mechanistic understanding of the early oxidation of two MCrAlY coatings, with a focus on the effect of the microstructure of the coatings. The two MCrAlY coatings used in this work have the same nominal composition but different microstructures, deposited by low-pressure plasma spraying (LPPS) and high velocity oxygen fuel (HVOF) spraying, respectively. LPPS and HVOF are two of the most frequently used thermal spraying techniques to manufacture MCrAIY coatings for industrial applications, and therefore the results in this work should give universal insights into the oxidation behaviour of many MCrAlY coatings during service. Characterisation of oxidation is implemented using correlative microscopy, which links together the observations and analysis from optical microscopy, scanning electron microscopy (SEM) and analytical transmission electron microscopy (TEM). The microstructure-dependent oxidation effects are then described from the perspective of oxidation kinetics, which includes the contribution of both lattice and grain boundary diffusion, to quantitatively illustrate the importance of certain microstructural features of the MCrAlY coatings in governing the transient oxidation behaviour. The analysis of the oxidation of the MCrAlY coatings is further extended to the Pt-diffused $Y / Y^{\prime}$ bond coat to explain the oxidation of this type of bond coat.

\section{Materials and Methods}

ANiCoCrAlY coatings were prepared by spraying ANiCoCrAIY powder (Amdry 365-2, Sulzer Metco) onto Hastelloy ${ }^{\circledR} X$ superalloy plates (55 $\times 30 \times 5$ $\mathrm{mm}^{3}$ ) using HVOF and LPPS, respectively. The thickness of the as-deposited HVOF and LPPS coating is $\sim 230 \mu \mathrm{m}$ and $200 \mu \mathrm{m}$, respectively. The relatively thick coatings are helpful to eliminating the effect of coating/substrate interfusion on early oxidation of the coatings. Table 1 shows the nominal compositions of the as-sprayed coatings and the Hastelloy ${ }^{\circledR} X$ superalloy 
substrate. The LPPS coating was then annealed in a vacuum tube furnace (Carbolite, UK) at $10^{-5}$ mbar at $1100^{\circ} \mathrm{C}$ for $2 \mathrm{~h}$. No post deposition annealing was applied to the HVOF coating to avoid undesirable grain growth. The coated superalloy plates were sliced into square-shape samples $\left(8 \times 8 \mathrm{~mm}^{2}\right)$ using a SiC abrasive cutting blade in a precision cut-off machine (Accutom 10, Struers). Prior to oxidation, the surfaces of the coatings were mechanically polished to a $1 \mu \mathrm{m}$ finish. This step produced a similar initial root-mean-square roughness $(\sim 0.05 \mu \mathrm{m})$ on all samples. Several Vickers micro-hardness indentations were placed into the surfaces as markers and then imaged using an optical microscope (BH2-UMA, Olympus) and SEM (Magellan 400 XHR, FEI). The recorded surface images allowed correlation of the same areas before and after oxidation to study possible site-specific oxidation. Oxidation of the coatings was performed in a $\mathrm{CM}^{\mathrm{T} M}$ furnace at $1150^{\circ} \mathrm{C}$ for 5 minutes in laboratory air, with rapid heating $\left(200^{\circ} \mathrm{C} / \mathrm{min}\right)$ and fan-assisted air cooling. The furnace had a thermocouple fitted in the centre of the chamber and the samples were placed next to the thermocouple. The thermocouple monitored the temperatures around the samples and synchronises the temperature data to the control program, which constantly adjust the input power to meet the temperature setting.

After oxidation, the phases present in the thermally grown $\mathrm{Al}_{2} \mathrm{O}_{3}$ scales were determined using photoluminescence piezospectroscopy (PLPS) on an InViaTM confocal Raman microscope (Renishaw, Gloucestershire, UK) fitted with a He-Ne laser source $(\lambda=633 \mathrm{~nm})$ according to the methodology described in the references [32]. This technique takes advantage of the high sensitivity of the $\mathrm{Cr}^{3+}$ fluorescence, even though the $\mathrm{Al}_{2} \mathrm{O}_{3}$ scale formed during the early oxidation stage is thin and sometimes buried underneath a duplex $(\mathrm{Ni}, \mathrm{Co})(\mathrm{Cr}, \mathrm{Al})_{2} \mathrm{O}-(\mathrm{Cr}, \mathrm{Al})_{2} \mathrm{O}_{3}$ transient oxide layer. Following PLPS measurements, the surfaces of the samples were sputtered with a thin layer of gold and examined using SEM from both top and oblique views to reveal the surface microstructure and topography of the oxides. In order to study the composition and microstructure of the oxides in greater details, crosssectional thin lamellae of the oxides were prepared by a focused ion beam (FIB, Helios NanoLab 660, FEI) and analysed using a scanning transmission electron microscope (STEM, TecnaiTM G2 200kV, FEI) equipped with an energy dispersive X-ray spectroscopy (EDS, X-MaxN 80T, Oxford Instruments) system. The details of STEM sample preparation can be found elsewhere [34]. But briefly, cross-sectional lamellae were first created by FIB milling through the oxides in the selected regions. The lamellae were then in-situ lifted out and welded to a copper grid using a combination of an OmniProbe micromanipulator and a gas injection system fitted in the FIB system, followed by thinning to an electron transparent thickness (< $100 \mathrm{~nm}$ ). Apart from STEM analysis, the cross-sectional thin lamellae were also analysed using transmission Kikuchi diffraction (TKD) in the Magellan 400 XHR SEM to map the phase distribution over the thickness of the oxides. The transmission geometry adopted in the TKD technique allows a minimum interaction volume between the impinging electrons and the samples being probed, thus 
1 improving the spatial resolution over the conventional electron 2 backscattered diffraction (EBSD). Details of the TKD technique can be found 3 elsewhere [35].

\section{$4 \quad 3$ Results}

5

6 7

\subsection{Microstructure of the as-deposited MNiCoCrAlY coatings}

Fig. 1 shows the microstructure of the AANiCoCrAlY coatings deposited by LPPS (Fig. 1 a) and HVOF (Fig. 1b), respectively. Both types of the coatings are dense, homogeneous and exhibit a two-phase microstructure ( $\beta$ and $y)$. However, their microstructures differ with respect to the grain size of the constituent phases, with the LPPS coating showing much coarser grains than the HVOF coating. The chemical compositions of the $\beta$ and $y$-phase, determined by EDS point analysis, are given in Table 2. The grain size and aspect ratio of the $\beta$ and $\gamma$-phase in the LPPS and HVOF coating, determined by quantitative image analysis, are given in Table $2 \underline{3}$. Oxide inclusions are hardly seen in either type of the coatings, which indicates that the coating material underwent negligible oxidation during the spraying process. This could be attributed to the low oxygen content during LPPS and the relatively low temperature and high velocity during HVOF, respectively.

\subsection{Surface morphology of the oxides}

Fig.2 shows the surface morphology and topography of the oxides grown on the LPPS coating. Correlation of the surface microstructure of the same area before and after oxidation shows that the oxides inherit the contours of the underlying metal grains, but the oxides on the $\beta$ and $y$-grains exhibit distinct surface morphologies. The surface of the oxide on the $y$-grains shows angular, faceted grains, but the surface of the oxide on the $\beta$-grains is characterised by whisker-type grains, which are typical microstructural features of metastable $\theta-\mathrm{Al}_{2} \mathrm{O}_{3}$ [32]. Surface topography revealed by the oblique view (Fig.2b) shows that the surface of the oxide on the $\beta$-grains is highly uneven, suggesting that the thickness of the oxide may vary substantially even over the surface of a single $\beta$-grain. The divergent surface morphologies of the oxides on the $\beta$ and $y$-grains are consistent with the observations reported by Levi et al [20]. The dependence of the oxide morphology on the microstructure of the underlying alloy, however, is not seen on the HVOF ANNiCoCrAlY coating (Fig.3). Instead, the oxide is rather homogeneous with tiny equiaxed grains $(\sim 60-300 \mathrm{~nm}$ ) densely compacted all over the coating surface.

\subsection{PLPS analysis of the $\mathrm{Al}_{2} \mathrm{O}_{3}$ scales}

Fig.4 shows the PLPS spectra of the $\mathrm{Al}_{2} \mathrm{O}_{3}$ scales grown on the $y$ (Fig.4a) and $\beta$-grains (Fig.4b) of the LPPS coating, respectively. It should be noted that there are two pre-conditions that allow the PLPS spectra of the $\mathrm{Al}_{2} \mathrm{O}_{3}$ scales 
on different phases to be collected separately with little ambiguity. First, the difference in morphology and thickness between the oxides on the $\beta$ and $y$-grains gives rise to different contrasts of the two types of the areas under the optical microscope. Second, the size of the focused laser spot is in the range of $\sim 3-5 \mu \mathrm{m}$, which is comparable to the grain size of the LPPS coating. The PLPS spectra of the $\mathrm{Al}_{2} \mathrm{O}_{3}$ scales on both $\beta$ and $\gamma$-grains show characteristic $\mathrm{R}$ lines (R1 and $\mathrm{R} 2$ ) of $a-\mathrm{Al}_{2} \mathrm{O}_{3}$ and $\mathrm{T}$ lines (T1 and T2) of $\theta-\mathrm{Al}_{2} \mathrm{O}_{3}$, suggesting that the $\mathrm{Al}_{2} \mathrm{O}_{3}$ scales on $\beta$ and $\gamma$-grains consist of a mixture of $\theta$ and $\mathrm{a}-\mathrm{Al}_{2} \mathrm{O}_{3}$. However, the relative intensities of the $\mathrm{T} 1$ and $\mathrm{T} 2$ lines collected from the $\beta$-grains are substantially higher than those on the $y$-grains, suggesting a significantly higher content of $\theta-\mathrm{Al}_{2} \mathrm{O}_{3}$ in the $\mathrm{Al}_{2} \mathrm{O}_{3}$ scales on the $\beta$-grains. The higher content of the $\theta-\mathrm{Al}_{2} \mathrm{O}_{3}$ on the $\beta$-grain is consistent with the previous findings that the $\beta$-grain has a large propensity to form $\theta-\mathrm{Al}_{2} \mathrm{O}_{3}$

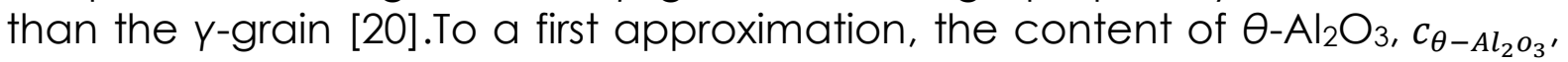
in the $\mathrm{Al}_{2} \mathrm{O}_{3}$ scale can be estimated by comparing the intensities of the $\mathrm{R}$ lines and $\mathrm{T}$ lines, given by [36]:

$$
c_{\theta-A l_{2} o_{3}}=\frac{A_{T 1}+A_{T 2}}{A_{R 1}+A_{R 2}+A_{T 1}+A_{T 2}}
$$

Where $A$ denotes the areas of the characteristic peaks obtained by fitting the PLPS spectra in WIRETM software (Renishaw, Gloucestershire, UK) by four mixed Gaussian-Lorentzian functions. The calculated $c_{\theta-\mathrm{Al}_{2} \mathrm{O}_{3}}$ in the $\mathrm{Al}_{2} \mathrm{O}_{3}$ scales on the $Y$ and $\beta$-grains of the LPPS coating is $3.26 \%$ and $50.1 \%$, respectively.

It should be noted that the above calculation is only a qualitative estimation, as it has been reported that the intensity of the $\theta-\mathrm{Al}_{2} \mathrm{O}_{3}$ is about 10 times higher than that of the $a-\mathrm{Al}_{2} \mathrm{O}_{3}$ [32]. However, the fact that the $a-\mathrm{Al}_{2} \mathrm{O}_{3}$ layer is buried underneath the $\mathrm{\theta}-\mathrm{Al}_{2} \mathrm{O}_{3}$ layer (which will be shown later) means that the intrinsic higher intensity of the $\mathrm{a}-\mathrm{Al}_{2} \mathrm{O}_{3}$ could be partially cancelled out as the intensity of the laser will decrease as it passes through the $\theta-\mathrm{Al}_{2} \mathrm{O}_{3}$ layer before reaching the underlying $a-\mathrm{Al}_{2} \mathrm{O}_{3}$ layer. This is expected to decrease the uncertainty of the calculation using Eq (1), although it is unlikely that the thin top $\theta-\mathrm{Al}_{2} \mathrm{O}_{3}$ layer could fully compensate the difference in luminescence intensity between $\theta-\mathrm{Al}_{2} \mathrm{O}_{3}$ and $\mathrm{a}-\mathrm{Al}_{2} \mathrm{O}_{3}$.

In contrast with the findings on the LPPS coating, the PLPS spectra of the $\mathrm{Al}_{2} \mathrm{O}_{3}$ scale on the HVOF coating only show single characteristic R 1 and R2 doublet of $\mathrm{a}-\mathrm{Al}_{2} \mathrm{O}_{3}$ (Fig.5), irrespective of the areas being probed. This suggests that the $\mathrm{Al}_{2} \mathrm{O}_{3}$ scale on the HVOF coating only contains $a-\mathrm{Al}_{2} \mathrm{O}_{3}$ after oxidation.

\subsection{TEM analysis of the oxide on the LPPS coating}

Fig. 6 shows the TEM analysis of the cross-section of the oxide on the LPPS ANiCoCrAIY coating. The oxide on the $Y$-grain is essentially multilayer, consisting of an outer $\mathrm{Ni} / \mathrm{Co} / \mathrm{Cr}$-rich layer ( $235 \mathrm{~nm}$ thick), an intermediate 
1 Cr-rich layer ( $\sim 26 \mathrm{~nm}$ thick) and an inner Al-rich layer ( $88 \mathrm{~nm}$ thick), as 2 confirmed by the contrast in the STEM annular dark field (STEM-ADF) image 3 (Fig.6a and b) and corresponding EDS mapping (Fig.6d, e, g, and h). 4 Selected area electron diffraction (SAED) conducted on a grain of the outer 5 layer shows the characteristic diffaction pattern of the spinel structure 6 (Fig.6c), suggesting that the outer layer is spinel. SAED analysis of the 7 intermediate $\mathrm{Cr}$-rich and inner Al-rich layer has not been successful due to 8 the extremely fine grains. However, high resolution TEM (HR-TEM) analysis of 9 both the intermediate $\mathrm{Cr}$-rich and inner Al-rich layers reveals a corundum 10 structure, as exemplified in Fig.6f. The combination of the HR-TEM, EDS analysis 11 and PLPS spectra suggests that the Cr-rich and Al-rich layer is mainly $12 \mathrm{a}-(\mathrm{Cr}, \mathrm{Al})_{2} \mathrm{O}_{3}$ and $\mathrm{a}-\mathrm{Al}_{2} \mathrm{O}_{3}$, respectively. The presence of the overwhelming $13 \mathrm{a}-\mathrm{Al}_{2} \mathrm{O}_{3}$ in the inner layer is expected, as the growing spinel reduces the 14 oxygen partial pressure at the oxide/metal interface and enables the $a-\mathrm{Al}_{2} \mathrm{O}_{3}$ 15 to form thermodynamically in preference to its metastable polymorphs (e.g. $\left.16 \theta-\mathrm{Al}_{2} \mathrm{O}_{3}\right)$. A string of intermittent voids are seen at the interface between the 17 outer spinel and the inner $(\mathrm{Cr}, \mathrm{Al})_{2} \mathrm{O}_{3}$ layer (Fiig.6b). The formation of these 18 interfacial voids is probably induced by the volumetric shrinkage associated 19 20 with the solid state reactions between the oxides [4]. The total thickness of the oxide is $\sim 350 \mathrm{~nm}$.

Unlike the multi-component oxide on the $y$-grains, the oxide on the $\beta$-grain, however, is comprised of only $\mathrm{Al}_{2} \mathrm{O}_{3}$, without any indication of the spinel formation seen on the $y$-grain, as indicated by the uniform contrast of the oxide (Fig.6a) and EDS analysis. The whisker-type morphology, as observed from the surface in Fig.2, can be also seen from the cross-section. The TKD phase map (Fig.6i) shows that the oxide near the metal/oxide interface is a- $\mathrm{Al}_{2} \mathrm{O}_{3}$. As a result, the substantial amount of $\theta-\mathrm{Al}_{2} \mathrm{O}_{3}$ detected by PLPS must be in the outer portion of the oxide scale. Attempts have been made to map the distribution of the $\theta-\mathrm{Al}_{2} \mathrm{O}_{3}$ over the thickness of the oxide using TKD. However, these have not been successful, probably due to the small grain size of the $\theta-\mathrm{Al}_{2} \mathrm{O}_{3}$. The oxide shows substantial variation in upward displacement and thickness (ranging from 315 to $585 \mathrm{~nm}$ ) along the lateral direction. The heterogeneities of the upward displacement and thickness of the oxide are in agreement with the observations of the uneven oxide surface on the $\beta$-grains shown in Fig. $2 \mathrm{~b}$. It is believed that this variation in upward displacement and thickness of the oxide is related to, at least to some extent, the local content of $\theta-\mathrm{Al}_{2} \mathrm{O}_{3}$. As the growth of $\theta-\mathrm{Al}_{2} \mathrm{O}_{3}$ is predominantly controlled by the outward diffusion of aluminium and the growth rate of $\theta-\mathrm{Al}_{2} \mathrm{O}_{3}$ is orders of magnitude higher than that of the $\mathrm{a}-\mathrm{Al}_{2} \mathrm{O}_{3}$ counterpart $[37,38]$, the oxide is expected to be thinner with smaller outward displacement in the areas where the content of $\theta-\mathrm{Al}_{2} \mathrm{O}_{3}$ is lower. Voids as large as $\sim 515 \mathrm{~nm}$ in the lateral direction can be seen at the oxide/metal interface or entrapped inside the oxide scale close to the interface (Fig.6a).

44 It should be noted that the microstructure and composition of the 45 ANiCoCrAlY coatings during oxidation is dynamic [39, 40], even for the 
1 relatively short oxidation period used in this study. During oxidation, the $\beta$ phase near the oxide/metal interface is gradually converted to the $y$-phase due to aluminium depletion induced by oxidation. Therefore, the oxide that is grown on the initial $\beta$-phase is eventually, at least partially, in contact with a layer of $y$-phase after oxidation, regardless of which phase the oxide initially grew on. For example, most of the subsurface regions of the $\beta$-grain shown in Fig.6a have been transformed to $Y$-phase (the brighter contrast), which can be also confirmed by the TKD phase-contrast map in Fig.6i. This phase transformation also makes especially important the correlation of the TEM analysis of the site-specific oxidation with the surface microstructure of the coating before oxidation to identify the relationship between the composition of the oxide and the respective metal phase of the underlying coating. On the other hand, it is also found that the extent of aluminium depletion varies along the lateral direction of the $\beta$-grain. For instance, while a small region in the centre of the $\beta$-grain remains as the $\beta$-phase, the remainder of the grain has been transformed to the $y$-phase. This phase transformation becomes more significant as the region of interest moves from the centre of the grain to the grain boundary (Fig.6a). This suggests that diffusion flux of aluminium in the grain boundary region is higher during oxidation.

\subsection{TEM analysis of the oxide on the HVOF coating}

Fig.7 shows the TEM analysis of the cross-section of the oxide on the HVOF coating. In contrast to the site-specific oxidation seen on the LPPS coating, the composition and microstructure of the oxide on the HVOF coating shows little dependence on the underlying metal phase and consists of exclusive a- $\mathrm{Al}_{2} \mathrm{O}_{3}$, as confirmed by a combination of TKD analysis (Fig.7d) as well as previous PLPS analysis (Fig.5). The oxide scale has a fairly uniform thickness ( $290 \mathrm{~nm}$ thick) and homogeneous microstructure along the lateral direction over the entire coating surface (Fig.7a). The microstructure of the $\mathrm{Al}_{2} \mathrm{O}_{3}$ scale consists of outer equiaxed grains and inner columnar grains. The columnar a- $\mathrm{Al}_{2} \mathrm{O}_{3}$ form distinctive imprints into the alloy with convex/concave shape edges at the $\mathrm{Al}_{2} \mathrm{O}_{3}$ grain boundaries. The presence of these columnar grains is a consequence of the inward growth of the $a-\mathrm{Al}_{2} \mathrm{O}_{3}$ grains [41-43]. Secondary-phase precipitates (the particles with bright contrast marked in Fig.7b) enriched with yttrium are found embedded in the oxide. Apart from forming Y-rich precipitates, EDS mapping (Fig.7C) over a selected area reveals that yttrium segregates to the grain boundaries of the oxide as well as the oxide/metal interface. The segregation of yttrium to the grain boundaries of the $\mathrm{Al}_{2} \mathrm{O}_{3}$ grains and subsequent formation of the $\mathrm{Y}$-rich particles are not seen in the oxide on the LPPS coating. This difference is expected, as the outward transportation of reactive elements from the underlying alloy to the interface and then to scale grain boundaries will not be realised until a protective, external $a-\mathrm{Al}_{2} \mathrm{O}_{3}$ scale is fully established [42]. The segregation of yttrium to the growing $\mathrm{Al}_{2} \mathrm{O}_{3}$ grain boundaries effectively blocks the outward diffusion of aluminium during oxidation and the oxidation becomes 
1 dominated by inward oxygen diffusion, as confirmed by the characteristic 2 columnar grains. The oxide/metal interface is intact, without the presence of 3 the large voids shown in Fig.6a.

\section{4. Discussion}

5 The findings in this work show that for a given composition, the microstructure 6 of the AANiCoCrAlY coating has a substantial impact on its oxidation 7 behaviour. For the LPPS coating with relative coarse grains, the $y$ and $\beta$ 8 phase show different oxidation behaviours. Oxidation of the $y$-phase is 9 manifested by formation of a multilayer oxide structure (the sequence of the 10 oxides from the gas/oxide to oxide/metal interface is determined by their 11 thermodynamic stability, with the less protective spinel on top and the most 12 thermodynamic stable $a_{-} \mathrm{Al}_{2} \mathrm{O}_{3}$ in contact with the metal). The oxidation of 13 the $\beta$-phase, however, is controlled by selective oxidation of aluminium and 14 subsequent formation of the oxide consisting of a mixture of $\theta$ and $a-\mathrm{Al}_{2} \mathrm{O}_{3}$. 15 The oxidation of the nanocrystalline HVOF coating, on the other hand, is 16 characterised by exclusive formation of an $\mathrm{a}_{-} \mathrm{Al}_{2} \mathrm{O}_{3}$ scale all over the surface, without any dependence of oxide composition on the underlying metal phases. These findings suggest that refinement of the ANNiCoCrAlY coating grain structure promotes the selective oxidation of aluminium on the $y$-phase and the formation of protective $a-\mathrm{Al}_{2} \mathrm{O}_{3}$ over both the $\beta$ and $\gamma$-phase, which in turn reduces the overall oxide growth rate and enhances oxidation resistance of the coating. The mechanistic interpretations of these findings will be explored in the following sections.

\subsection{Effect of coating microstructure on selective oxidation of aluminium}

In theory, growth of exclusive $\mathrm{Al}_{2} \mathrm{O}_{3}$ on the $y$-phase will only occur if the following two criteria are met: first, an external $\mathrm{Al}_{2} \mathrm{O}_{3}$ scale is originally developed on the $Y$-phase; second, following the establishment of the original $\mathrm{Al}_{2} \mathrm{O}_{3}$ scale, the diffusion-supply of aluminium towards the interface must be sufficiently rapid or more than sufficient to compensate the instantaneous loss of the aluminium consumed during oxidation in order to maintain the growth of the exclusive $\mathrm{Al}_{2} \mathrm{O}_{3}$.

According to Wagner's criterion, the minimum concentration of aluminium in 33 the $y$-phase to originally develop an external $\mathrm{Al}_{2} \mathrm{O}_{3}$ scale on the $y$-phase, $34 N_{A l(\min )}^{\gamma}$, is given by [30]:

$$
N_{A l(\min )}^{\gamma}=\left(\frac{\pi g N_{O}^{\gamma} D_{O}^{\gamma} V_{m}^{\gamma}}{3 D_{A l}^{\gamma} V_{m}^{A l_{2} O_{3}}}\right)^{\frac{1}{2}}
$$

35 Where $g$ is a constant; $V_{m}^{\gamma}$ and $V_{m}^{\mathrm{Al}_{2} \mathrm{O}_{3}}$ is the molar volume of the $y$-phase and $36 \mathrm{Al}_{2} \mathrm{O}_{3}$, respectively; $N_{O}^{\gamma} D_{O}^{\gamma}$ is the oxygen permeability in the $\gamma$-phase; $D_{A l}^{\gamma}$ is the 37 diffusion coefficient of aluminium in the $y$-phase. 
1 Once the initial external $\mathrm{Al}_{2} \mathrm{O}_{3}$ scale is established, the minimum

2 concentration of aluminium in the $Y$-phase, $N^{\prime \gamma}{ }_{A l(m i n)}$, to maintain the growth 3 of exclusive $\mathrm{Al}_{2} \mathrm{O}_{3}$ is given by [29]:

$$
N_{A l(\text { min })}^{\prime \gamma}=\frac{V_{m}^{\gamma}}{V_{m}^{A l_{2} O_{3}}}\left(\frac{\pi k_{p}^{A l_{2} O_{3}}}{D_{A l}^{\gamma}}\right)^{\frac{1}{2}}
$$

4 where $k_{p}^{\mathrm{Al}_{2} \mathrm{O}_{3}}$ is the parabolic rate constant of $\mathrm{Al}_{2} \mathrm{O}_{3}$.

5 It should be noted that Eqs (2) and (3) are derived based on single-phase 6 alloy and they are in principle not applicable to multiphase alloys. However, 7 the observations in Fig.6 suggest that for a relatively short time of oxidation 8 the $Y$ and $\beta$-phase are oxidised independently and their interaction is, 9 therefore, believed to be minimal. As a result, Eqs (2) and (3) could be still 10 reasonable approximations for the $y$-phase at the initial oxidation stage.

11 For a polycrystalline aggregate, the overall diffusion flux of a solute is the sum 12 of the fluxes through the bulk lattice and grain boundary. As a result, $D_{A l}^{\gamma}$ can 13 be written as:

$$
D_{A l}^{\gamma}=D_{A l}^{L}(1-f)+D_{A l}^{G B} f
$$

14 Where $D_{A l}^{L}$ and $D_{A l}^{G B}$ are diffusion coefficients of aluminium through the lattice 15 and along the grain boundary, respectively. $f$ is the ratio of the area of the 16 grain boundary, given by:

$$
f=\frac{2 \delta}{d}
$$

17 Where $\delta$ is the grain boundary thickness ( $0.6 \mathrm{~nm}$ for nickel alloys [44]) and $d$ 18 is the grain size.

19 Mathematical description of $D_{A l}^{G B}$ requires quantitative data on the geometry 20 of the $Y$-grains and the types of the grain boundaries (Apart from 21 misorientation angles, in a two-phase AANiCoCrAlY coating a $Y$-grain can be 22 bordered by either $\beta$-grains ( $y / \beta$ grain boundaries) or $y$-grains ( $y / Y$ grain 23 boundaries). In order to extract these data, EBSD was performed on both 24 coatings and the results of the LPPS coating are shown in Fig.8 (EBSD indexing 25 of the HVOF coating was not successful, and the reason will be discussed 26 later). The EBSD analysis shows that that most of the $y$-grains and $\beta$-grains 27 show equiaxed morphology parallel to the surface, which is in agreement 28 with the quantitative image analysis reported in Table.3z. Furthermore, the 29 EBSD analysis also shows that the grain boundaries are predominately 30 high-angle grain boundaries and on average a $Y$-grain is bordered by five $31 \mid \beta$-grains and one $y$-grain (based on image analysis of over $50 y$-grains and 
1 their surrounding grains; the twin boundaries inside the $y$-grains are not

$$
D_{A l}^{G B}=\frac{1}{6} D_{A l}^{\gamma \gamma}+\frac{5}{6} D_{A l}^{\gamma \beta}
$$

3 Where $D_{A l}^{\gamma \gamma}$ and $D_{A l}^{\gamma \beta}$ are diffusion coefficients of aluminium along the $Y / Y$ and $4 \quad Y / \beta$ grain boundaries.

5 Combine Eqs (2-6), we have:

$$
\begin{gathered}
N_{A l(\min )}^{\gamma}=\left(\frac{\pi g N_{O}^{\gamma} D_{O}^{\gamma} V_{m}^{\gamma}}{3\left[D_{A l}^{L}\left(1-\frac{2 \delta}{d}\right)+\left(\frac{1}{6} D_{A l}^{\gamma \gamma}+\frac{5}{6} D_{A l}^{\gamma \beta}\right) \frac{2 \delta}{d}\right] V_{m}^{A l_{2} O_{3}}}\right)^{\frac{1}{2}} \\
N_{A l(\min )}^{\prime \gamma}=\frac{V_{m}^{\gamma}}{V_{m}^{A l_{2} O_{3}}}\left(\frac{\pi k_{p}^{A l_{2} O_{3}}}{D_{A l}^{L}\left(1-\frac{2 \delta}{d}\right)+\left(\frac{1}{6} D_{A l}^{\gamma \gamma}+\frac{5}{6} D_{A l}^{\gamma \beta}\right) \frac{2 \delta}{d}}\right)^{\frac{1}{2}}
\end{gathered}
$$

$6 \quad N_{A l(\min )}^{\gamma}$ and $N^{\prime}{ }_{A l(\min )}^{\gamma}$ can be then normalised as:

$$
\begin{aligned}
& \frac{N_{A l(\min )}^{\gamma}}{N_{A l(\text { min })}^{\gamma \nu}}=\frac{\left(\frac{\pi g N_{O}^{\gamma} D_{O}^{\gamma} V_{m}^{\gamma}}{3\left[D_{A l}^{L}\left(1-\frac{2 \delta}{d}\right)+\left(\frac{1}{6} D_{A l}^{\gamma \gamma}+\frac{5}{6} D_{A l}^{\gamma \beta}\right) \frac{2 \delta}{d}\right] V_{m}^{A l_{2} O_{3}}}\right)^{\frac{1}{2}}}{\left(\frac{\pi g N_{O}^{\gamma} D_{O}^{\gamma} V_{m}^{\gamma}}{3 D_{A l}^{L} V_{m}^{A l_{2} O_{3}}}\right)^{\frac{1}{2}}} \\
& \frac{N_{A l(\min )}^{\prime \gamma}}{N_{A l(\min )}^{\prime \prime l}}=\frac{\frac{V_{m}^{\gamma}}{V_{m}^{A l_{2} O_{3}}}\left(\frac{\pi k_{p}^{A l_{2} O_{3}}}{D_{A l}^{L}\left(1-\frac{2 \delta}{d}\right)+\left(\frac{1}{6} D_{A l}^{\gamma \gamma}+\frac{5}{6} D_{A l}^{\gamma \beta}\right) \frac{2 \delta}{d}}\right)^{\frac{1}{2}}}{\frac{V_{m}^{\gamma}}{V_{m}^{A l_{2} O_{3}}}\left(\frac{\pi k_{p}^{A l_{2} O_{3}}}{D_{A l}^{L}}\right)^{\frac{1}{2}}}
\end{aligned}
$$

7 Where $N_{A l(\min )}^{\gamma_{L}}$ and $N_{A l(\min )}^{\prime \gamma_{L}}$ represent the minimum concentration of 8 aluminium to originally develop an exclusive $\mathrm{Al}_{2} \mathrm{O}_{3}$ layer and maintain the 9 subsequent growth of exclusive $\mathrm{Al}_{2} \mathrm{O}_{3}$, respectively, when only lattice diffusion 10 of aluminium is involved (e.g. in case of a single-crystal $y$-alloy).

11 Eqs 9 and 10 can be simplified as: 
1 Eq (11) shows that $\frac{N_{A l(\min )}^{\gamma}}{N_{A l(\min )}^{\gamma}}$ and $\frac{N_{A l(\min )}^{\prime \gamma}}{N_{A l(\min )}^{\prime{ }^{\prime}}}$ share the same mathematical 2 description. As a result, only the relationship between $\frac{N_{A l(\min )}^{\gamma}}{N_{A l(\min )}^{\gamma L}}$ and the grain 3 size, $d$, is discussed in the following section, as the same relationship applies to $4 \quad \frac{N_{A l(m i n)}^{\prime \gamma}}{N^{\prime \prime L}(\operatorname{lin})}$.

5 According to Eq (11), for a given $\frac{D_{A l}^{\gamma \gamma}}{D_{A l}^{L}}$ and $\frac{D_{A l}^{\gamma \beta}}{D_{A l}^{L}}$ the relationship between $\frac{N_{A l(\min )}^{\gamma}}{N_{A l(\min )}^{\gamma /}}$ 6 and $d$ can be predicted. Although quantitative relationship between $D_{A l}^{\gamma \gamma}, D_{A l}^{\gamma \beta}$ 7 and $D_{A l}^{L}$ are not known, it is reasonable to assume that $D_{A l}^{\gamma \gamma}$ and $D_{A l}^{\gamma \beta}$ are orders 8 of magnitudes higher than $D_{A l}^{L}\left(D_{A l}^{\gamma \beta} \gg D_{A l}^{L}\right.$ and $\left.D_{A l}^{\gamma \gamma} \gg D_{A l}^{L}\right)$. Fig.9 gives four 9 examples of the evolution of $\frac{N_{A l(m i n)}^{\gamma}}{N_{A l(m i n)}^{\gamma L}}$ as a function of $d$, where $\frac{D_{A l}^{\gamma \gamma}}{D_{A l}^{L}}$ and $\frac{D_{A l}^{\gamma \beta}}{D_{A l}^{L}}$ are 10 assigned four different sets of values $\left(\frac{D_{A l}^{\gamma \gamma}}{D_{A l}^{L}}=100, \frac{D_{A l}^{\gamma \beta}}{D_{A l}^{L}}=200 ; \frac{D_{A l}^{\gamma \gamma}}{D_{A l}^{L}}=200, \frac{D_{A l}^{\gamma \beta}}{D_{A l}^{L}}=100\right.$; $\frac{D_{A l}^{\gamma \gamma}}{D_{A l}^{L}}=100, \frac{D_{A l}^{\gamma \beta}}{D_{A l}^{L}}=1000$ and $\left.\frac{D_{A l}^{\gamma \gamma}}{D_{A l}^{L}}=1000, \frac{D_{A l}^{\gamma \beta}}{D_{A l}^{L}}=100\right)$. It is seen that in all cases $N_{A l(\min )}^{\gamma}$ decreases with decreasing $d$ and this effect becomes more

\subsection{Critical grain size of the $Y$-phase to form exclusive $\mathrm{Al}_{2} \mathrm{O}_{3}$}

27 While it has been shown that decreasing grain size of the ANNiCoCrAlY 28 coating promotes selective oxidation of aluminium on the $y$-phase, the 29 critical grain size, below which oxidation of the $y$-phase will transform to 30 growth of exclusive $\mathrm{Al}_{2} \mathrm{O}_{3}$, remains to be determined, at least for the 
1 oxidation temperature used in this study. The schematic illustration of this

2 critical grain size, $d_{c}$, is given in Fig.10. Here we consider three types of 3 aluminium diffusion fluxes towards the surface: diffusion through the $y$-lattice, $4 J_{A l}^{\gamma}$, diffusion through the $\beta$-lattice, $J_{A l}^{\beta}$ and diffusion along the $Y / \beta$ boundary, $5 J_{A l}^{G B}$, in the order of $J_{A l}^{\gamma}<J_{A l}^{\beta}<J_{A l}^{G B}$ (thermodynamic equilibrium in a multi-phase 6 alloy (e.g. the two-phase ANiCoCrAlY alloy) imposes strict restriction on 7 diffusion of metal components between different phases, which prevents the 8 interaction of $J_{A l}^{\gamma}, J_{A l}^{\beta}$ and $J_{A l}^{G B}$ in the alloy). The resulting profile of the 9 instantaneous aluminium flux reaching the surface and corresponding oxide 10 microstructure are also superimposed in Fig.10. If the minimum flux of 11 aluminium required forming exclusive $\mathrm{Al}_{2} \mathrm{O}_{3}$ is defined as $J_{A l}^{\min }$, we will have $12 J_{A l}^{\gamma}<J_{A l}^{\min }<J_{A l}^{\beta}<J_{A l}^{G B}$, as our observations have shown that oxidation of the $\beta$ 13 phase is characterised by selective oxidation of aluminium, but oxidation of 14 the $\mathrm{Y}$-phase is featured by growth of $\mathrm{Al}_{2} \mathrm{O}_{3}$, $(\mathrm{Ni}, \mathrm{Co})(\mathrm{Cr}, \mathrm{Al})_{2} \mathrm{O}_{4}$ and $(\mathrm{Cr}, \mathrm{Al})_{2} \mathrm{O}_{3}$. 15 As the aluminium flux over the coating surface is expected to be continuous, 16 there must exists a segment with a length of $\frac{d_{c}}{2}$, bounded by the $y / \beta$ 17 boundary and the intersection between the aluminium flux profile and $J_{A l}^{\min }$, 18 still having an aluminium flux higher than $J_{A l}^{\min }$. In this region, formation of exclusive $\mathrm{Al}_{2} \mathrm{O}_{3}$ is still possible even the region is within the $y$-phase. In an extreme scenario when the grain size of $Y$-phase is decreased to $d_{c}$ or below, the formation of $(\mathrm{Ni}, \mathrm{Co})(\mathrm{Cr}, \mathrm{Al})_{2} \mathrm{O}_{4}$ and $(\mathrm{Cr}, \mathrm{Al})_{2} \mathrm{O}_{3} \mathrm{Ni} / \mathrm{Co} / \mathrm{Cr}$-rich transient oxides could be completely inhibited.

To confirm the prediction above, the composition of the oxide across the $Y / \beta$ boundary region shown in Fig.6a is examined in details, and the corresponding EDS analysis is shown in Fig.11. It is found that unlike the multilayer nature of the oxide formed in the inner part of the $y$-grain far away from the grain boundary, the oxide in the vicinity of the grain boundary $(\sim 350 \mathrm{~nm}$ in the lateral direction) is free of base metal elements (e.g. Ni and $\mathrm{Co}$, Figl $1 \mathrm{~b}$ and $\mathrm{C}$ ), suggesting that the oxide in this region is $\mathrm{Al}_{2} \mathrm{O}_{3}$. This region corresponds to the segment with a length of $\frac{d_{c}}{2}$ shown in Fig.10. This also predicts that when the grain size is reduced to $700 \mathrm{~nm}$, there will be no $\mathrm{Ni} / \mathrm{Co} / \mathrm{Cr}$-rich transient oxides formed on the $y$-phase. The prediction is in good agreement with our observations of the nanocrystalline HVOF coating showing formation of exclusive $\mathrm{Al}_{2} \mathrm{O}_{3}$ all over the surface. It should be noted that the prediction $d_{c} \approx 700 \mathrm{~nm}$ is made based on the analysis of the specific $Y / \beta$-grain and $Y / \beta$ boundary shown in Fig. 11. In reality, $d_{c}$ may span a certain range as $J_{A l}^{\beta} J_{A l}^{\gamma}$ and $J_{A l}^{G B}$ could depend on many factors (e.g. crystallographic orientation of $\gamma / \beta$-grain, grain boundary misorientation, grain boundary composition and the type of $\mathrm{Al}_{2} \underline{O}_{3}$ developed $\left(\theta\right.$ or $\left.\left.a-\mathrm{Al}_{2} \mathrm{O}_{3}\right)\right)$, which may nevertheless vary from grain to grain and boundary to boundary in the NiCoCrAlY coatings. 
1 Strictly speaking, the discussion above only considers the scenario when the

$2 y$-grains are equiaxed. When the grain geometry deviates from equiaxed 3 morphology, it is less useful to predict the oxide composition simply using the 4 grain size given by Fig.10, without taking the shape factor of the grain into 5 account. For grains with elongated surface shape (aspect ratios much larger 6 than 1), as long as the widths of the grains are no larger than $d_{c}$, formation of 7 exclusive $\mathrm{Al}_{2} \mathrm{O}_{3}$ is still expected even though the length or grain size could be 8 larger than $d_{c}$. The implication here is that for a given grain size, elongated $Y$ 9 grains are more effective than equiaxed grains to form exclusive $\mathrm{Al}_{2} \mathrm{O}_{3}$. 10 Therefore, apart from the nanoscale grain size, the presence of the large amount of the long, narrow $\mathrm{Y}$-grains in the HVOF coating further promotes the formation of exclusive $\mathrm{Al}_{2} \mathrm{O}_{3}$ even though the lengths of the grains, and sometimes the grain size, are larger than $d_{c}$.

\subsection{Comparison of the microstructures the $\mathrm{Al}_{2} \mathrm{O}_{3}$ scales on the $\beta$-phases}

The current work has also shown that while oxidation of the $\beta$-phase in both LPPS and HVOF coatings is characterised by selective oxidation of aluminium, the phase compositions and microstructure of the $\mathrm{Al}_{2} \mathrm{O}_{3}$ scales are rather different. The oxide formed on the $\beta$-grains of the LPPS coating consists of $a$ mixture of $\theta(\sim 50.1 \%)$ and $a-\mathrm{Al}_{2} \mathrm{O}_{3}$, while the oxide formed on the $\beta$-grains of the HVOF coating is exclusive $a-\mathrm{Al}_{2} \mathrm{O}_{3}$. This suggests that the microstructure of the HVOF coating is also beneficial to the earlier establishment of an $a-\mathrm{Al}_{2} \mathrm{O}_{3}$ scale.

In theory, $\mathrm{a}-\mathrm{Al}_{2} \mathrm{O}_{3}$ originates from two sources: one is the phase transformation from the metastable $\mathrm{Al}_{2} \mathrm{O}_{3}$ precursors; the other is from direct nucleation of a- $\mathrm{Al}_{2} \mathrm{O}_{3}$ and subsequent grain growth. While the effect of the microstructure on the former is not clear (it is actually difficult to determine if metastable $\mathrm{Al}_{2} \mathrm{O}_{3}$ indeed formed on the HVOF coating), it has been known that processing methods that introduce defects to the metal substrates (e.g. grain refinement and cold work) could provide more heterogeneous nucleation sites for oxides [23, 42]. The high-density grain boundaries in the nanocrystalline HVOF coating increases the number of sites available for heterogeneous nucleation of $\mathrm{a}-\mathrm{Al}_{2} \mathrm{O}_{3}$ and, therefore, facilitate earlier establishment of an $a-\mathrm{Al}_{2} \mathrm{O}_{3}$ scale. On the other hand, while both LPPS and HVOF involve using thermal/kinetic energy to strike particles onto the substrate, the extremely high velocity and relatively low temperature (e.g. spray particles in a plastic rather than a melted state) using in the HVOF spraying means that the particles undergo more "cold deformation" upon impact with the substrate [45]. Apart from grain refinement, the severe plastic deformation at relative low temperature is likely to introduce more crystallographic defects (e.g. dislocations) into the deposited coatings and therefore provide more heterogeneous nucleation sites for $a-\mathrm{Al}_{2} \mathrm{O}_{3}$. Fig. 12 shows a bright-field TEM image (Fig.12a) of the as-deposited HVOF coating and the corresponding diffraction pattern (Fig.12b) of a $\beta$-grain. The diffraction spots are elongated and diffuse, which is attributed to the 
1 distortions of the lattice associated with the presence of the large number of the dislocations. The significant cold work also causes the Kikuchi patterns of the HVOF coating to be diffuse and unsuccessful EBSD indexing. In sum, it is suggested that the large number of the crystallographic defects, including grain boundaries and dislocations, in the HVOF coating promotes the preferable nucleation of the $a-\mathrm{Al}_{2} \mathrm{O}_{3}$ and shortens the transient oxidation period. It is expected that the similar effect is also present in NiCoCrAlY coatings deposited by high velocity air fuel (HVAF) spraying which uses lower deposition temperatures and involves more cold deformation of the particles than HVOF [46].

Another difference in oxidation behaviour of the $\beta$-phase between the LPPS and HVOF coating is that while there are large voids at the interface between the oxide and the $\beta$-phase in the LPPS coating, the oxide/metal interface in the HVOF coating is intact. It is known that voids could form at the oxide/metal interface during selective oxidation of the Ni-rich $\beta$-NiAl based alloys and coatings [47]. Experimental and theoretical analyses have shown that the intrinsic mechanisms for formation of these interfacial voids are associated with vacancy injection (the Kirkendall effect) and their subsequent coalescence due to the non-reciprocal diffusion of the metallic elements in the multicomponent alloys [47, 48] (e.g. the differential diffusion of nickel and aluminium in Ni-rich $\beta$-NiAl at $1150^{\circ} \mathrm{C}$, in which inward diffusion of nickel is more than three times faster than the outward diffusion of aluminium [49]). For the ANNiCoCrAlY coatings studied in this work, the smaller grain size of the nanocrystalline HVOF coating allows a greater diffusion flux of aluminium from the alloy to the surface, which effectively mitigates the Kirkendall effect and the propensity of subsequent void formation at the interface. Furthermore, the slower oxidation rate and the inward oxide growth mechanism of the $\beta$-phase on the HVOF coating, which resulted from earlier establishment of a protective $a-\mathrm{Al}_{2} \mathrm{O}_{3}$ scale and subsequent segregation of yttrium at the growing oxide grain boundaries, also helps to prevent vacancy condensation at the oxide/metal interface [19]. In addition, the segregation of the yttrium to the oxide/metal interface in the HVOF coating diminishes the driving force for detrimental impurity segregation (e.g. sulphur) at the oxide/metal interface and prevents vacancies from rapid coalescence [42]. Once formed, some of the interfacial voids could be undercut by the subsequently formed oxide around the peripheries of the voids and then entrapped inside the oxide [50], resulting in the formation of the voids inside the bottom part of the oxide on the $\beta$-phase in the LPPS coating.

\subsection{Implication to oxidation of Pt-diffused $Y / Y^{\prime}$ bond coats}

The findings in this work also provide insights into understanding the oxidation of the Pt-diffused $Y / Y^{\prime}$ bond coat [51, 52]. This type of bond coat consists of an Al/Pt-poor $Y$-phase matrix and Al/Pt-rich $Y^{\prime}$-precipitates. Representative chemical compositions of the $Y$ and $Y^{\prime}$-phase in the coating surface region 
reported by Zhao et al are given in Table.43 [52]. The relatively low concentration of aluminium (8.2 at.\%) and platinum (1 1.8 at.\%) in the $y$-phase is believed insufficient to form an exclusive $\mathrm{Al}_{2} \mathrm{O}_{3}$ scale. This argument can be supported by the facts that formation of Ni-rich transient oxides (e.g. spinel) have been found on bulk Ni-Al-Pt alloys with even higher aluminium and platinum concentrations than those of the $Y$-phase in the coating counterparts $[53,54]$. However, the Pt-diffused $Y / Y^{\prime}$ bond coat is generally reported to have good oxidation resistance by forming a pure and adherent $\mathrm{Al}_{2} \mathrm{O}_{3}$ scale over the coating surface $[52,55,56]$. This paradox is attributed to the intrinsic difference in microstructure between the Pt-diffused $Y / Y^{\prime}$ bond coats and the bulk alloys. The Pt-diffused $Y / Y^{\prime}$ bond coat, especially its surface region, is characterised by the presence of numerous fine, nanoscale $Y^{\prime}$ precipitates dispersed in the $y$-matrix $[51,57]$. Fig. 13 shows an EBSD inverse pole figure map of an as-deposited Pt-diffused $Y / Y^{\prime}$ bond coat, in which nanostructured grains are clearly seen in the surface region of the coating. This unique microstructure is associated with the Pt-diffusion induced recystallisation and subsequent precipitation process during the fabrication of the coating [51]. The great number of grain/phase boundaries provides numerous fast diffusion paths of aluminium at the initial stage of the oxidation and therefore benefits the establishment of an exclusive $\mathrm{Al}_{2} \mathrm{O}_{3}$ scale. The $\mathrm{Ni}$ Pt-Al alloys used in the literature for oxidation study, on the other hand, are generally fabricated by arc melting and featured by coarse grains up to millimetres in diameter $[53,54]$ Therefore, the contribution of fast aluminium diffusion along the alloy grain boundary to the overall oxidation of the alloy is negligible and the resulting diffusion flux of aluminium is therefore not sufficient to form exclusive $\mathrm{Al}_{2} \mathrm{O}_{3}$.

27

28

\section{Conclusions}

The early oxidation behaviour of a HVOF and LPPS ANNiCOCrAlY coating at $1150^{\circ} \mathrm{C}$ has been studied. The following conclusions can be drawn from this work.

1. The LPPS coating with relatively coarse-grains shows site-specific oxidation behaviour. The oxide on the $Y$-phase shows a multi-layer structure, consisting of outer $(\mathrm{Ni}, \mathrm{Co})(\mathrm{Cr}, \mathrm{Al})_{2} \mathrm{O}_{4}$, intermediate $(\mathrm{Cr}, \mathrm{Al})_{2} \mathrm{O}_{3}$ and inner $a-\mathrm{Al}_{2} \mathrm{O}_{3}$. The oxide on the $\beta$-phase is composed of a mixture of $\theta$ and $a-\mathrm{Al}_{2} \mathrm{O}_{3}$.

2. The nanocrystalline HVOF coating shows formation of an exclusive a$\mathrm{Al}_{2} \mathrm{O}_{3}$ scale all over the surface, without any dependence of oxide composition on the underlying metal phases.

3. Refinement of the AANiCoCrAlY coating microstructure promotes the selective oxidation of aluminium on the $y$-phase. This effect is associated with the fast diffusion of aluminium along the $Y / \beta$ grain boundaries, which contributes to a significant amount of the diffusion flux of aluminium in the nanocrystalline HVOF coating and therefore 


\section{Acknowledgements}

reduces the threshold of the aluminium content in the $y$-phase to form exclusive $\mathrm{Al}_{2} \mathrm{O}_{3}$.

4. It is predicated that oxidation of the $y$-phase would transform from growth of $\mathrm{Al}_{2} \mathrm{O}_{3}$ along with $(\mathrm{Ni}, \mathrm{Co})(\mathrm{Cr}, \mathrm{Al})_{2} \mathrm{O}_{4}$ and $(\mathrm{Cr}, \mathrm{Al})_{2} \mathrm{O}_{3}$ to selective oxidation of aluminium when the size of the $y$-grain is reduced to $700 \mathrm{~nm}$, provided that the grain is equiaxed. An elongated shape of the $y$-grain is beneficial to the formation of exclusive $\mathrm{Al}_{2} \mathrm{O}_{3}$.

5. The large amount of the crystallographic defects, including grains boundaries and dislocations, in the HVOF coating increases the number of sites available for heterogeneous nucleation of $a-\mathrm{Al}_{2} \mathrm{O}_{3}$ and, therefore, facilitate earlier establishment of an $a-\mathrm{Al}_{2} \mathrm{O}_{3}$ scale. Formation of interface voids are inhibited in the HVOF coating, which is attributed to the small grain size of the coating, early establishment of a protective $a-\mathrm{Al}_{2} \mathrm{O}_{3}$ and associated segregation of yttrium to the grain boundaries of the growing oxide as well as metal/oxide interface.

6. The contribution of grain boundaries to aluminium diffusion can be also used to explain the difference in oxidation behaviour between the Pt-diffused $Y / Y^{\prime}$ bond coats and their alloy counterparts.

The authors would like to acknowledge Nicholas Curry, Nicolaie Markocsan, Per Nylen from Production Technology Centre, University West, Sweden for supply of the samples. The authors are grateful to Mr. Simon McCormack for proof-reading the manuscript.

\section{4}

25 26

\section{References}

1. G.W. Goward, Progress in coatings for gas turbine airfoils. Surface \& Coatings Technology, 1998. 108(1-3). 73-79.

2. J.T. Demasimarcin and D.K. Gupta, Protective Coatings in the Gas-Turbine Engine. Surface \& Coatings Technology, 1994. 68. 1-9.

3. N.P. Padture, M. Gell, and E.H. Jordan, Thermal barrier coatings for gas-turbine engine applications. Science, 2002. 296(5566). 280-284.

4. A.G. Evans, D.R. Mumm, J.W. Hutchinson, G.H. Meier, and F.S. Pettit, Mechanisms controlling the durability of thermal barrier coatings. Progress in Materials Science, 2001. 46(5). 505-553.

5. D.R. Clarke and C.G. Levi, Materials design for the next generation thermal barrier coatings. Annual Review of Materials Research, 2003. 33. 383-417.

6. M.J. Pomeroy, Coatings for gas turbine materials and long term stability issues. Materials \& Design, 2005. 26(3). 223-231.

7. D. Naumenko, V. Shemet, L. Singheiser, and W.J. Quadakkers, Failure mechanisms of thermal barrier coatings on MCrAlY-type bondcoats associated with the formation of the thermally grown oxide. Journal of Materials Science, 2009. 44(7). 1687-1703.

8. T.J. Nijdam and W.G. Sloof, Effect of $Y$ distribution on the oxidation kinetics of NiCoCrAlY bond coat alloys. Oxidation of Metals, 2008. 69(1-2). 1-12.

9. U. Schulz, M. Menzebach, C. Leyens, and Y.Q. Yang, Influence of substrate material on oxidation behavior and cyclic lifetime of EB-PVD TBC systems. Surface \& Coatings Technology, 2001. 146. 117-123. 
10. W. Brandl, H.J. Grabke, D. Toma, and J. Kruger, The oxidation behaviour of sprayed MCrAlY coatings. Surface \& Coatings Technology, 1996. 86(1-3). 41-47.

11. W.G. Sloof and T.J. Nijdam, On the high-temperature oxidation of MCrA/Y coatings. International Journal of Materials Research, 2009. 100(10). 1318-1330.

12. D. Toma, W. Brandl, and U. Koster, Studies on the transient stage of oxidation of VPS and HVOF sprayed MCrAlY coatings. Surface \& Coatings Technology, 1999. 120. 8-15.

13. P. Richer, M. Yandouzi, L. Beauvais, and B. Jodoin, Oxidation behaviour of CoNiCrAlY bond coats produced by plasma, HVOF and cold gas dynamic spraying. Surface \& Coatings Technology, 2010. 204(24). 3962-3974.

14. J. Toscano, D. Naumenko, A. Gil, L. Singheiser, and W.J. Quadakkers, Parameters affecting TGO growth rate and the lifetime of TBC systems with MCrAlY-bondcoats. Materials and Corrosion-Werkstoffe Und Korrosion, 2008. 59(6). 501-507.

15. T.J. Nijdam, G.H. Marijnissen, E. Vergeldt, A.B. Kloosterman, and W.G. Sloof, Development of a pre-oxidation treatment to improve the adhesion between thermal barrier coatings and NiCoCrA/Y bond coatings. Oxidation of Metals, 2006. 66(5-6). 269-294.

16. A. Gil, V. Shemet, R. Vassen, M. Subanovic, J. Toscano, D. Naumenko, L. Singheiser, and W.J. Quadakkers, Effect of surface condition on the oxidation behaviour of MCrAlY coatings. Surface \& Coatings Technology, 2006. 201 (7). 3824-3828.

17. J. Toscano, R. Vassen, A. Gil, M. Subanovic, D. Naumenko, L. Singhelser, and W. Quadakkers, Parameters affecting TGO growth and adherence on MCrAly-bond coats for TBC's. Surface \& Coatings Technology, 2006. 201 (7). 3906-3910.

18. T.J. Nijdam, C. Kwakernaak, and W.G. Sloof, The effects of alloy microstructure refinement on the short-term thermal oxidation of NiCoCrAlY alloys. Metallurgical and Materials Transactions a-Physical Metallurgy and Materials Science, 2006. 37A(3). 683693.

19. W.J. Quadakkers, A.K. Tyagi, D. Clemens, R. Anton, and L. Singheiser, The significance of bond coat oxidation for the life of TBC coatings. Elevated temperature coatings: science and technology III, edited by J.M. Hampikian and N.B. Dahotre, TMS, Warrendale, PA, USA, 1999. 119.

20. C.G. Levi, E. Sommer, S.G. Terry, A. Catanoiu, and M. Ruhle, Alumina grown during deposition of thermal barrier coatings on NiCrAlY. Journal of the American Ceramic Society, 2003. 86(4). 676-685.

21. A.H. Hever, D.B. Hovis, J.L. Smialek, and B. Gleeson, Alumina Scale Formation: A New Perspective. Journal of the American Ceramic Society, 2011. 94. S146-S153.

22. A.H. Hever, T. Nakagawa, M.Z. Azar, P.B. Hovis, J.L. Smialek, B. Gleeson, N.D.M. Hine, H. Guhl, H.S. Lee, P. Tangney, W.M.C. Foulkes, and M.W. Finnis, On the growth of Al2O3 scales. Acta Materialia, 2013.61(18). 6670-6683.

23. C.S. Giggins and F.S. Pettit, Oxidation of Ni-Cr-Al Alloys between 1000 Degrees and 1200 Degrees C. Journal of the Electrochemical Society, 1971. 118(11). 1782-\&.

24. G.R. Wallwork and A.Z. Hed, Some Limiting Factors in the Use of Alloys at High Temperatures. Oxidation of Metals, 1971.3(2). 14.

25. T.J. Nijdam, L.P.H. Jeurgens, and W.G. Sloof, Promoting exclusive alpha-Al2O3 growth upon high-temperature oxidation of NiCrAl alloys: experiment versus model predictions. Acta Materialia, 2005. 53(6). 1643-1653.

26. T.J. Nijdam, L.P.H. Jeurgens, and W.G. Sloof, Effect of partial oxygen pressure on the initial stages of high-temperature oxidation of gamma-NiCrAl alloys. Materials at High Temperatures, 2003. 20(3). 311-318.

27. T.J. Nijdam, L.P.H. Jeurgens, and W.G. Sloof, Modelling the thermal oxidation of ternary alloys - Compositional changes in the alloy and the development of oxide phases. Acta Materialia, 2003. 51(18). 5295-5307.

28. T.J. Nijdam, L.P.H. Jeurgens, J.H. Chen, and W.G. Sloof, On the microstructure of the initial oxide grown by controlled annealing and oxidation on a NiCoCrAlY bond coating. Oxidation of Metals, 2005. 64(5-6). 355-377.

29. C. Wagner, Theoretical Analysis of the Diffusion Processes Determining the Oxidation Rate of Alloys. Journal of the Electrochemical Society, 1952. 99(10). 369-380. 
30. C. Wagner, Reaktionstypen Bei Der Oxydation Von Legierungen. Zeitschrift Fur Elektrochemie, 1959. 63(7). 772-790.

31. Z.Y. Liu, W. Gao, K.L. Dahm, and F.H. Wang, Oxidation behaviour of sputter-deposited Ni-Cr-Al micro-crystalline coatings. Acta Materialia, 1998. 46(5). 1691-1700.

32. V.K. Tolpygo and D.R. Clarke, Microstructural study of the theta-alpha transformation in alumina scales formed on nickel-aluminides. Materials at High Temperatures, 2000. 17(1). 59-70.

33. Y.H. Sohn, K. Vaidyanathan, M. Ronski, E.H. Jordan, and M. Gell, Thermal cycling of EBPVD/MCrAlY thermal barrier coatings: II. Evolution of photo-stimulated luminescence. Surface \& Coatings Technology, 2001. 146. 102-109.

34. R.M. Langford and A.K. Petford-Long, Preparation of transmission electron microscopy cross-section specimens using focused ion beam milling. Journal of Vacuum Science \& Technology a-Vacuum Surfaces and Films, 2001. 19(5). 2186-2193.

35. A. Garner, A. Gholinia, P. Frankel, M. Gass, I. MacLaren, and M. Preuss, The microstructure and microtexture of zirconium oxide films studied by transmission electron backscatter diffraction and automated crystal orientation mapping with transmission electron microscopy. Acta Materialia, 2014. 80. 159-171.

36. X. Wang, G. Lee, and A. Atkinson, Investigation of TBCs on turbine blades by photoluminescence piezospectroscopy. Acta Materialia, 2009. 57(1). 182-195.

37. G.C. Rybicki and J.L. Smialek, Effect of the Theta-Alpha-Al2O3 Transformation on the Oxidation Behavior of Beta-Nial+Zr. Oxidation of Metals, 1989. 31(3-4). 275-304.

38. M.W. Brumm and H.J. Grabke, The Oxidation Behavior of Nial .l. PhaseTransformations in the Alumina Scale during Oxidation of Nial and Nial-Cr Alloys. Corrosion Science, 1992.33(11). 1677-\&.

39. Y. Chen, X. Zhao, Y. Dang, P. Xiao, N. Curry, N. Markocsan, and P. Nylen, Characterization and understanding of residual stresses in a NiCoCrAlY bond coat for thermal barrier coating application. Acta Materialia, 2015. 94. 1-14.

40. Y. Chen, X. Zhao, M. Bai, L. Yang, C. Li, L. Wang, J.A. Carr, and P. Xiao, A mechanistic understanding on rumpling of a NiCoCrAlY bond coat for thermal barrier coating applications. Acta Materialia, 2017. 128. 31-42.

41. J.R. Blachere, E. Schumann, G.H. Meier, and F.S. Pettit, Textures of alumina scales on FeCrAl alloys. Scripta Materialia, 2003. 49(9). 909-912.

42. B.A. Pint, Experimental observations in support of the dynamic-segregation theory to explain the reactive-element effect. Oxidation of Metals, 1996. 45(1-2). 1-37.

43. B.A. Pint, A.J. Garratt-Reed, and L.W. Hobbs, Analytical electron-microscopy study of the breakdown of alpha-Al(2)O(3) scales formed on oxide dispersion-strengthened alloys. Oxidation of Metals, 2001. 56(1-2). 119-145.

44. D. Prokoshkina, V.A. Esin, G. Wilde, and S.V. Divinski, Grain boundary width, energy and self-diffusion in nickel: Effect of material purity. Acta Materialia, 2013. 61(14). 5188-5197.

45. E. Lugscheider, C. Herbst, and L.D. Zhao, Parameter studies on high-velocity oxy-fuel spraying of MCrAlY coatings. Surface \& Coatings Technology, 1998. 108(1-3). 16-23.

46. HVAF Process Overview. http://www.hvaf.com.

47. M.W. Brumm and H.J. Grabke, Oxidation Behavior of Nial .2. Cavity Formation beneath the Oxide Scale on Nial of Different Stoichiometries. Corrosion Science, 1993. 34(4). 547-\&.

48. Z. Suo, D.V. Kubair, A.G. Evans, D.R. Clarke, and V.K. Tolpygo, Stresses induced in alloys by selective oxidation. Acta Materialia, 2003. 51 (4). 959-974.

49. S. Shankar and L.L. Seigle, Interdiffusion and Intrinsic Diffusion in Nial (Delta) Phase of Al-Ni System. Metallurgical Transactions a-Physical Metallurgy and Materials Science, 1978. 9(10). 1467-1476.

50. B.A. Pint, On the formation of interfacial and internal voids in alpha-Al2O3 scales. Oxidation of Metals, 1997. 48(3-4). 303-328.

51. X. Zhao, B. Cernik, C.C. Tang, S.P. Thompson, and P. Xiao, Stress evolution in a Ptdiffused gamma/gamma ' bond coat after oxidation. Surface \& Coatings Technology, 2014. 247. 48-54. 
52. X. Zhao, I.P. Shapiro, and P. Xiao, Spinel formation in thermal barrier systems with a Ptenriched gamma-Ni+gamma '-Ni3Al bond coat. Surface \& Coatings Technology, 2008. 202(13). 2905-2916.

53. Y. Chen, X. Zhao, M. Bai, A. Chandio, R. Wu, and P. Xiao, Effect of platinum addition on oxidation behaviour of gamma/gamma ' nickel aluminide. Acta Materialia, 2015. 86. 319-330.

54. B. Gleeson, N. Mu, and S. Hayashi, Compositional factors affecting the establishment and maintenance of Al2O3 scales on Ni-Al-Pt systems. Journal of Materials Science, 2009. 44(7). 1704-1710.

55. Y. Zhang, D.A. Ballard, J.P. Stacy, B.A. Pint, and J.A. Haynes, Synthesis and oxidation behavior of platinum-enriched gamma+gamma' bond coatings on Ni-based superalloys. Surface \& Coatings Technology, 2006. 201 (7). 3857-3861.

56. Y. Zhang, B.A. Pint, J.A. Haynes, and I.G. Wright, A platinum-enriched gamma+gamma ' two-phase bond coat on Ni-based superalloys. Surface \& Coatings Technology, 2005. 200(5-6). 1259-1263.

57. J.A. Haynes, B.A. Pint, Y. Zhang, and I.G. Wright, Comparison of the cyclic oxidation behavior of beta-NiAl, beta-NiPtAl and gamma-gamma ' NiPtAl coatings on various superalloys. Surface \& Coatings Technology, 2007. 202(4-7). 730-734. 
$A_{R 1}$ PLPS peak area of the $\mathrm{R} 1$ peak of a- $-\mathrm{Al}_{2} \mathrm{O}_{3}$

$A_{T 1}$ PLPS peak area of the T1 peak of $\theta-\mathrm{Al}_{2} \mathrm{O}_{3}$

$c_{\theta-\mathrm{Al}_{2} \mathrm{O}_{3}}$ content of $\theta-\mathrm{Al}_{2} \mathrm{O}_{3}$

$d_{c}$ critical grain size of $\gamma$ to form

exclusive $\mathrm{Al}_{2} \mathrm{O}_{3}$

$D_{A l}^{L}$ diffusion coefficient of aluminium through the $\gamma$ lattice

$D_{A l}^{\gamma \beta}$ diffusion coefficient of aluminium along the $\gamma / \beta$ boundary

$D_{O}^{\gamma}$ diffusion coefficient of oxygen in $\gamma$

$J_{A l}^{G B}$ diffusion flux along the $\gamma / \beta$ boundary

$J_{A l}^{\beta}$ diffusion flux through the $\beta$-lattice

$k_{p}^{\mathrm{Al}_{2} \mathrm{O}_{3}}$ parabolic rate $\mathrm{Al}_{2} \mathrm{O}_{3}$

$N_{A l(\min )}^{\gamma}$ the minimum concentration of aluminium in $\gamma$ to originally develop an external $\mathrm{Al}_{2} \mathrm{O}_{3}$ scale

$N_{A l(\min )}^{\gamma_{L}}$ the minimum concentration of aluminium in $\gamma$ to originally develop an exclusive $\mathrm{Al}_{2} \mathrm{O}_{3}$ layer when only lattice diffusion of aluminium is involved

$V_{m}^{\gamma}$ molar volume of $\gamma$

$\delta$ grain boundary thickness
$A_{R 2}$ PLPS peak area of the R2 peak of $\mathrm{a}-\mathrm{Al}_{2} \mathrm{O}_{3}$

$A_{T 2}$ PLPS peak area of the T2 peak of $\theta-\mathrm{Al}_{2} \mathrm{O}_{3}$

$d$ Grain size

$D_{A l}^{G B}$ diffusion coefficient of aluminium along the grain boundary

$D_{A l}^{\gamma} \quad$ overall effective diffusion coefficient of aluminium in $\gamma$

$D_{A l}^{\gamma \gamma}$ diffusion coefficient of aluminium along the $\gamma / \gamma$ boundary

$f$ ratio of the area of the grain boundary

$J_{A l}^{\min }$ the minimum flux of aluminium required forming exclusive $\mathrm{Al}_{2} \mathrm{O}_{3}$

$J_{A l}^{\gamma}$ diffusion flux through the $\gamma$-lattice

$N_{O}^{\gamma}$ solubility of oxygen in $\gamma$

$N^{\prime}{ }_{A l(\min )}^{\gamma}$ the minimum concentration of aluminium in $\gamma$ to maintain the growth of exclusive $\mathrm{Al}_{2} \mathrm{O}_{3}$

$N^{\prime}{ }_{A l(\min )}^{\gamma_{L}}$ the minimum concentration of aluminium in $\gamma$ to maintain the growth of exclusive $\mathrm{Al}_{2} \mathrm{O}_{3}$ when only lattice diffusion of aluminium is involved $V_{m}^{\mathrm{Al}_{2} \mathrm{O}_{3}}$ molar volume of $\mathrm{Al}_{2} \mathrm{O}_{3}$ 
Fig.1 Microstructure of (a) LPPS and (b) HVOF coatings. The LPPS coating shows coarser grains than the HVOF coating. Both coatings consist of $\beta$-phase (grey contrast) and $y$-phase (light contrast).

Fig.2 Surface morphology of the LPPS coating after oxidation: (a) top view and (b) oblique view. The coating shows site-specific oxidation. The inset at the top left corner of Fig.2a is an optical image of the same area prior to oxidation, which is used to correlate the morphology of the oxide with the underlying metal phase before oxidation. The metal phases below the oxides are indicated.

Fig.3 Surface morphology of the HVOF coating after oxidation: (a) top view (b) a higher magnification image of the area within the white rectangle in Fig.4a. The coating does not show phase-specific oxidation.

Fig.4 PLPS spectra of the $\mathrm{Al}_{2} \mathrm{O}_{3}$ scale on (a) $\gamma$-phase and (b) $\beta$-phase of the LPPS coating surface

Fig.5 PLPS spectra of the $\mathrm{Al}_{2} \mathrm{O}_{3}$ scale on HVOF coating surface.

Fig.6 TEM analysis of the cross-section of the oxide on the LPPS coating: (a) STEM-ADF image giving an overview of the oxide on the $Y$ and $\beta$-phase; the white spots between the protective platinum layer and the oxides are the gold particles sputtered on the surface of the oxide to increase electrical conductivity for SEM and FIB analysis. The $\beta$-phase near the oxide/metal interface has been transformed to $Y$-phase (termed as "newly-formed $Y$ in the figure) due to Al depletion during oxidation. (b) a high magnification STEM-ADF image of the oxide on the $y$-phase, showing the multi-layer nature of the oxide; (c) diffraction pattern of a grain in the outer layer of the oxide on the $y$-phase, showing typical spinel structure; ( $d, e, g$ and $h$ ) EDS mapping over the area in (b) showing the presence of all base metal elements $((\mathrm{Ni}+\mathrm{Co}):(\mathrm{Cr}+\mathrm{Al}) \approx 0.5)$ in the outer layer of the oxide, chromium and aluminium $(\mathrm{Cr}: \mathrm{Al} \approx 1.5)$ in the middle layer of the oxide and exclusive aluminium in the inner layer of the oxide; $(f)$ a high-resolution TEM image of the inner layer of the oxide on the $y$-phase. The corresponding FFT pattern shows typical corundum structure. (i) TKD phase-contrast map across the oxide/metal interface, showing that the oxide near the metal/oxide interface is $\mathrm{a}-\mathrm{Al}_{2} \mathrm{O}_{3}$.

Fig.7 TEM analysis of the cross-section of the oxide on the HVOF coating: (a) STEM-ADF image giving an overview of the oxide. The white spots between the protective platinum layer and the oxides are the gold particles sputtered on the surface of the oxide to increase electrical conductivity for SEM and FIB analysis. (b) a high magnification STEM-ADF image showing the presence of the precipitates enriched with yttrium (c) EDS mapping over the area in the black rectangle in Fig.7b showing segregation of yttrium to the oxide grain 
boundaries and oxide/metal interface (d) TKD phase-contrast map with red colour representing $\mathrm{a}-\mathrm{Al}_{2} \mathrm{O}_{3}$ and blue colour $\mathrm{Y}$-Ni.

Fig. 8 EBSD analysis of the as-deposited LPPS coating: (a) phase-contrast map and (b) inverse pole figure colour map.

Fig.9 Evolution of $\frac{N_{A l(\min )}^{\gamma}}{N_{A l(\min )}^{\gamma /}}$ as a function of the grain size of the $y$-phase for four different sets of grain boundary diffusion coefficients. The grain size of the $y$-phase in the LPPS and HVOF coating used in this study is also indicated.

Fig.10 Schematic illustration of the aluminium flux to the surface of $y$-grain, $\beta$-grain and across the $\beta / Y$ grain boundary during oxidation. The minimum aluminium flux to form exclusive $\mathrm{Al}_{2} \mathrm{O}_{3}$ is indicated and the corresponding oxide compositions are also superimposed. Due to the higher aluminium flux along the $\beta / Y$ grain boundary and the continuity of the flux profile over the surface, the oxide within the segments, $\frac{d_{c}}{2}$, remains exclusive $\mathrm{Al}_{2} \mathrm{O}_{3}$ even though the regions are within the $y$-grain.

Fig.11 TEM analysis of the oxide across the $Y / \beta$ grain boundary shown in Fig.6a: (a) STEM-ADF image showing morphology and element contrast (b, c) EDS mapping showing distribution of cobalt and nickel over the area within the white rectangle in Fig. 11 a. The oxide near the $Y / \beta$ boundary is free of nickel and cobalt, with existence of only aluminium and oxygen.

Fig.12 TEM analysis of the as-deposited HVOF coating: (a) bright-field image showing the presence of the larger number of dislocations (b) diffraction pattern of the $\beta$-grain marked with " $D$ " in Fig.12a. The diffraction spots are elongated and diffuse.

Fig.13. Cross-sectional EBSD inverse pole figure map (RD) of an as-deposited Pt-diffused $Y / Y^{\prime}$ coating showing the nanostructured grains in the surface region 
Click here to download high resolution image
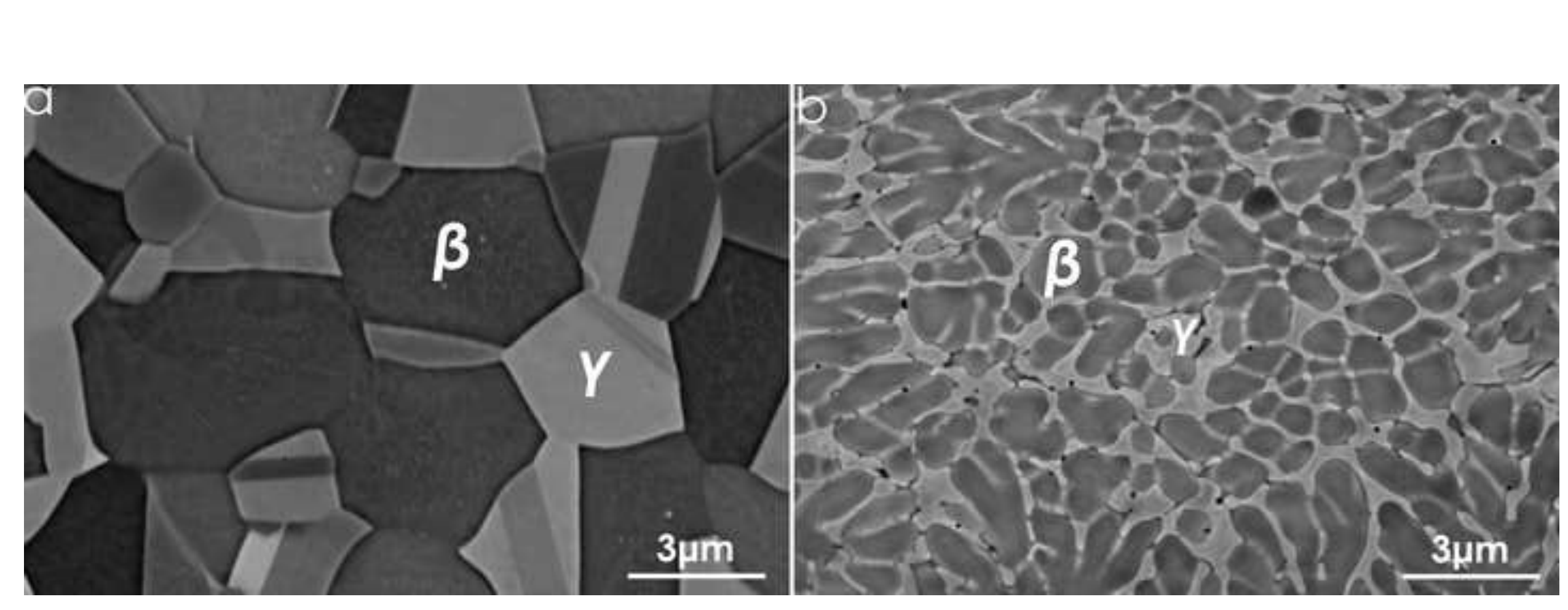

Click here to download high resolution image 

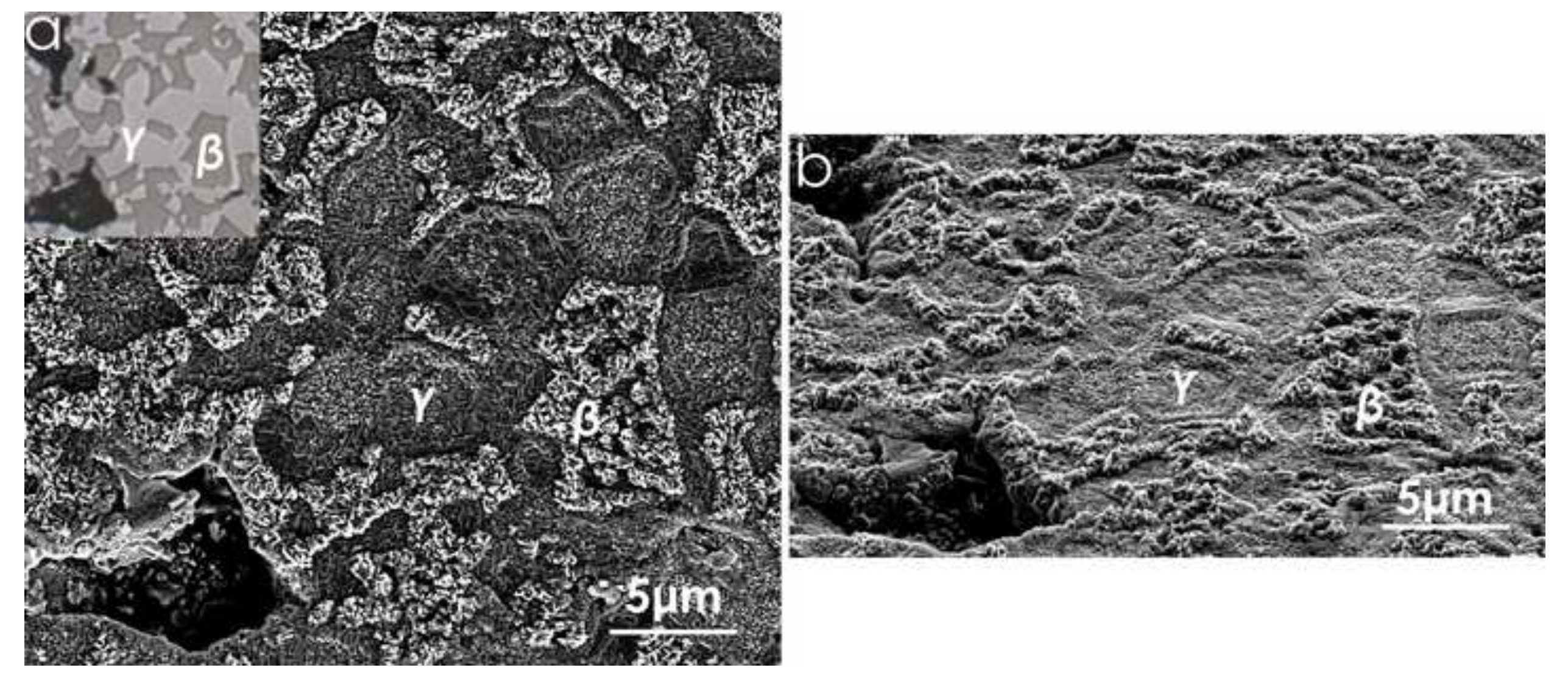

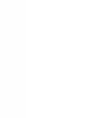



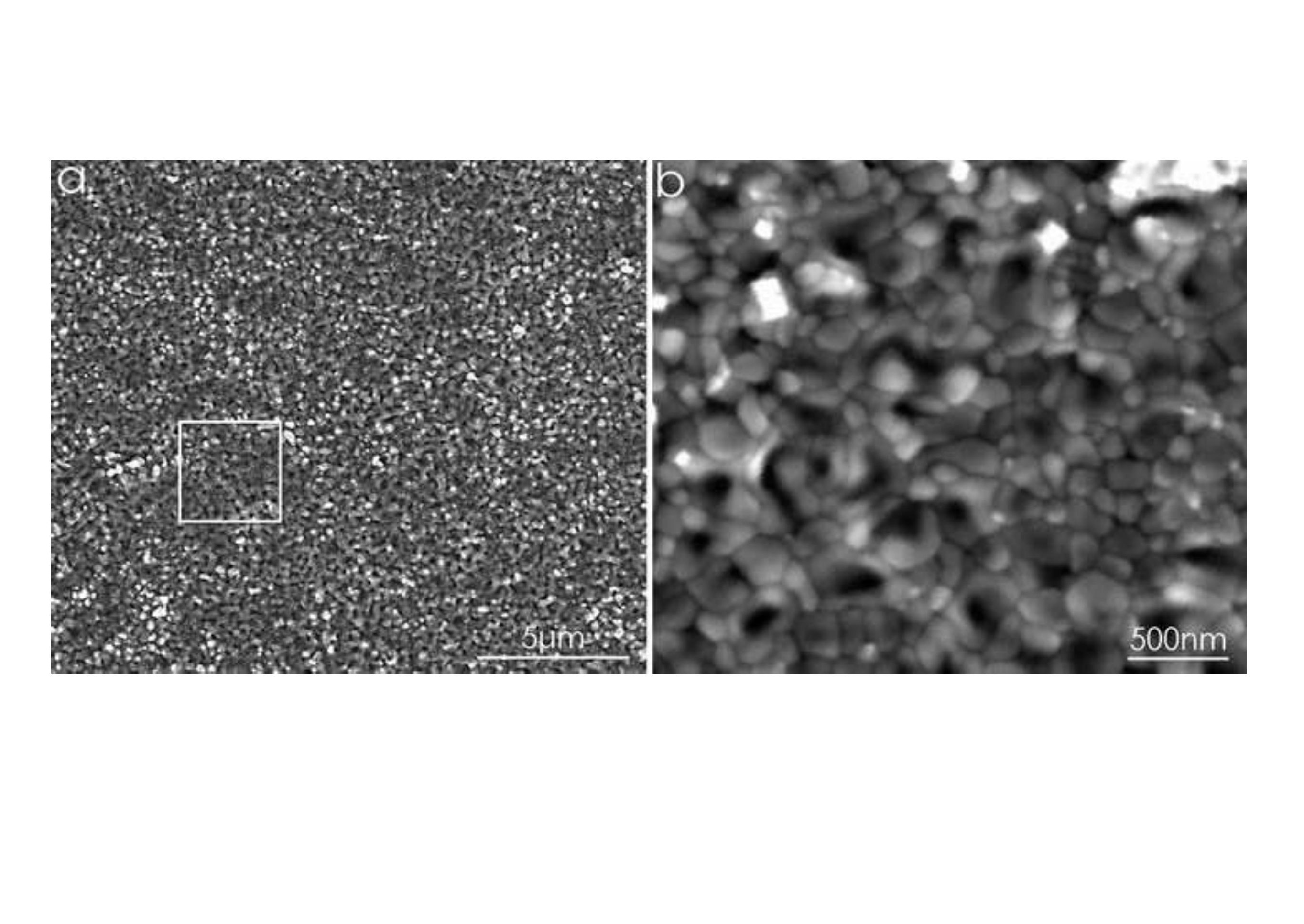

(1)

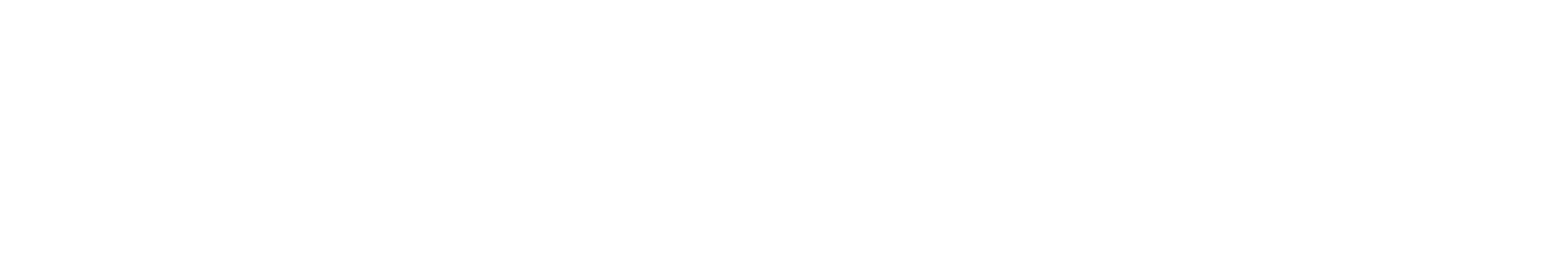




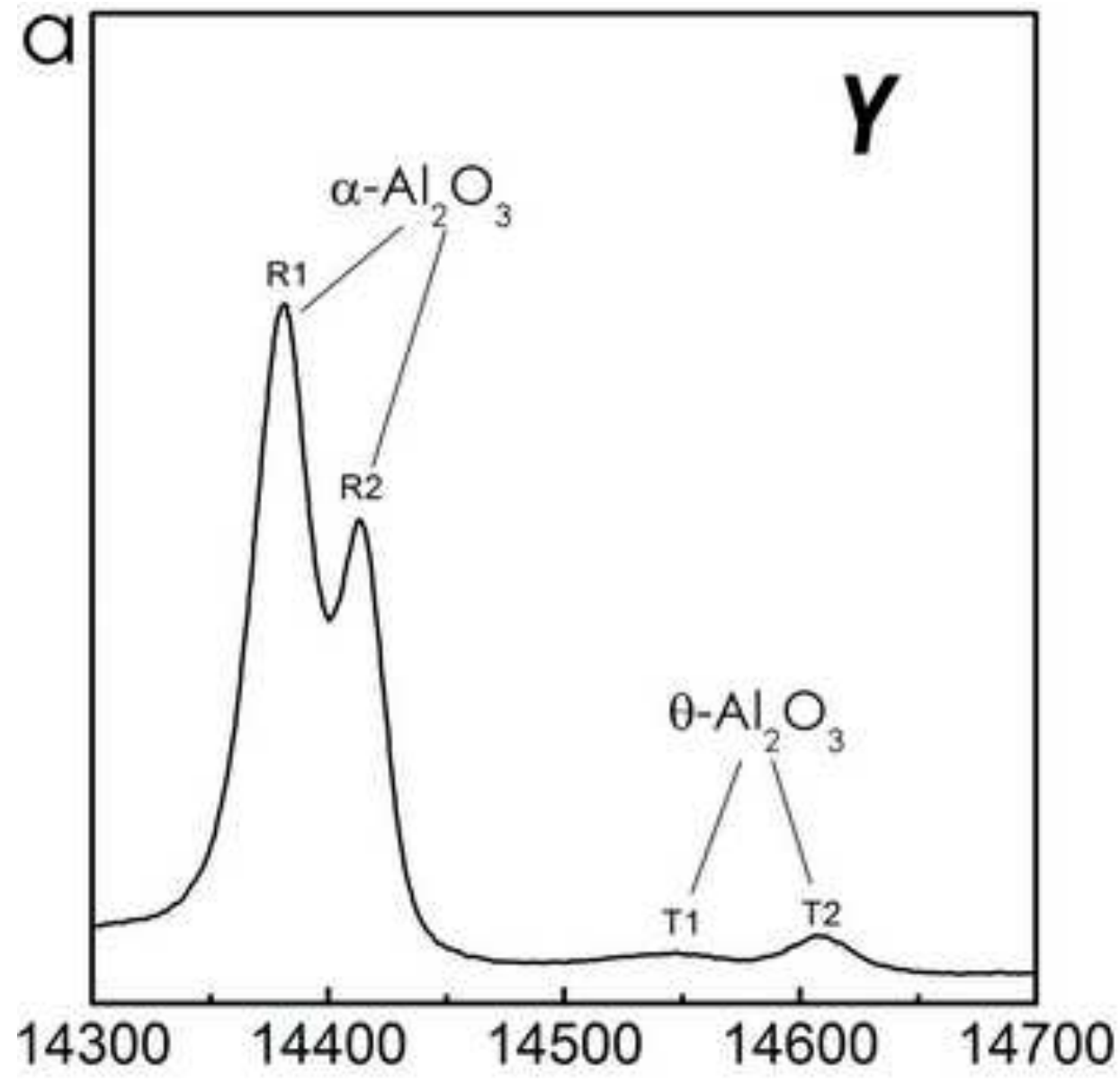

Wavenumber $\left(\mathrm{cm}^{-1}\right)$

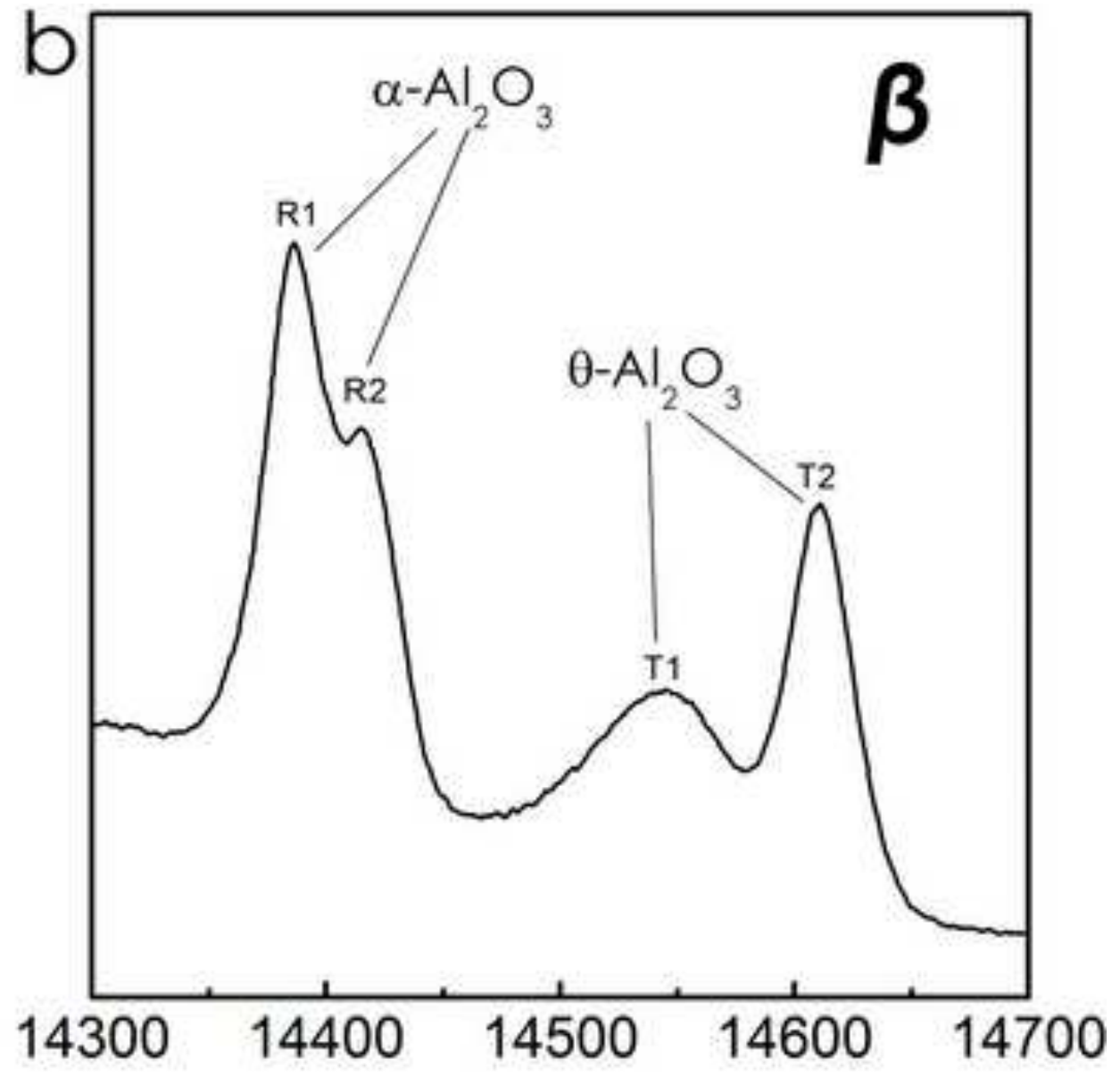

Wavenumber $\left(\mathrm{cm}^{-1}\right)$ 
Fig. 5
Click here to download high resolution image

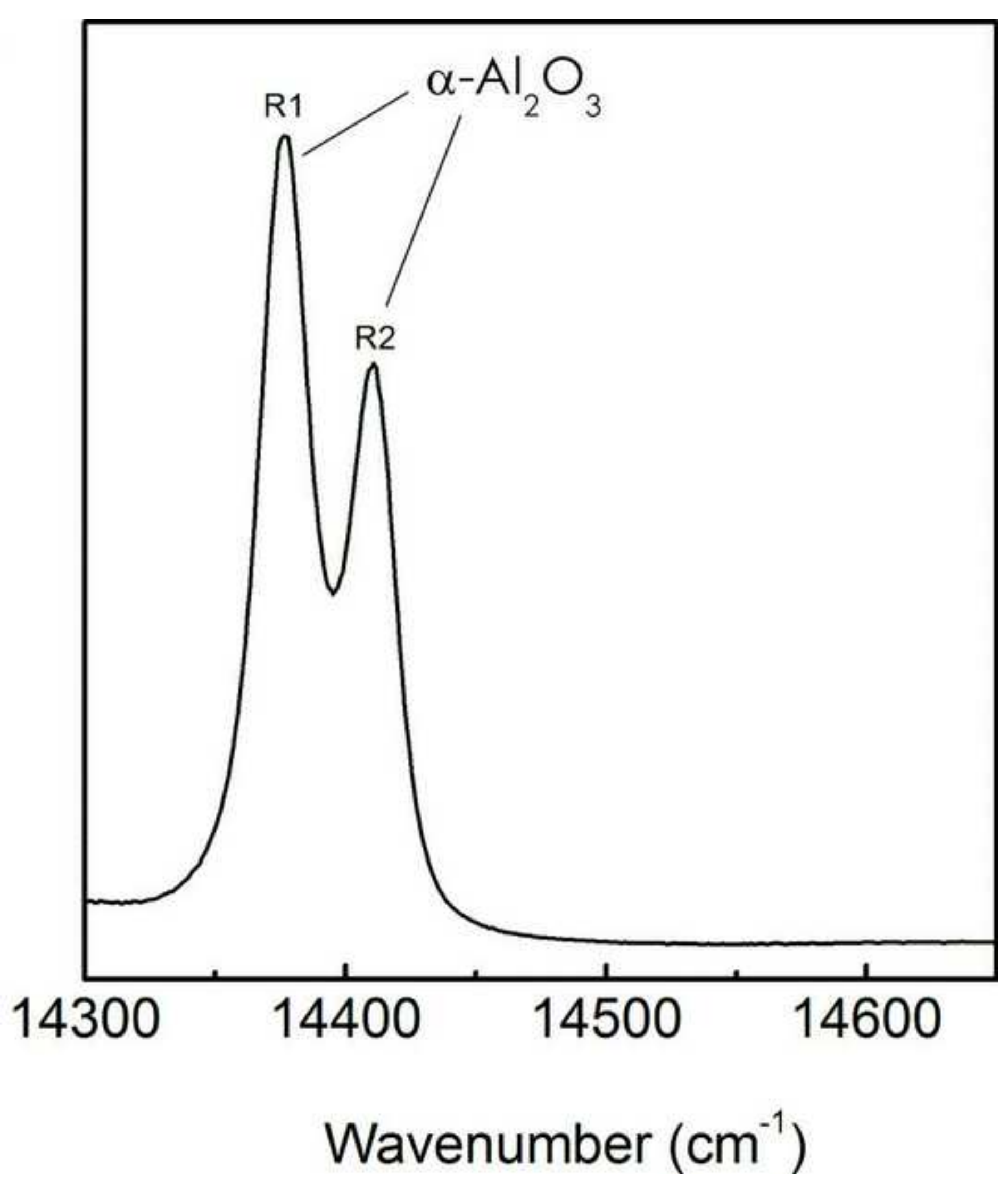



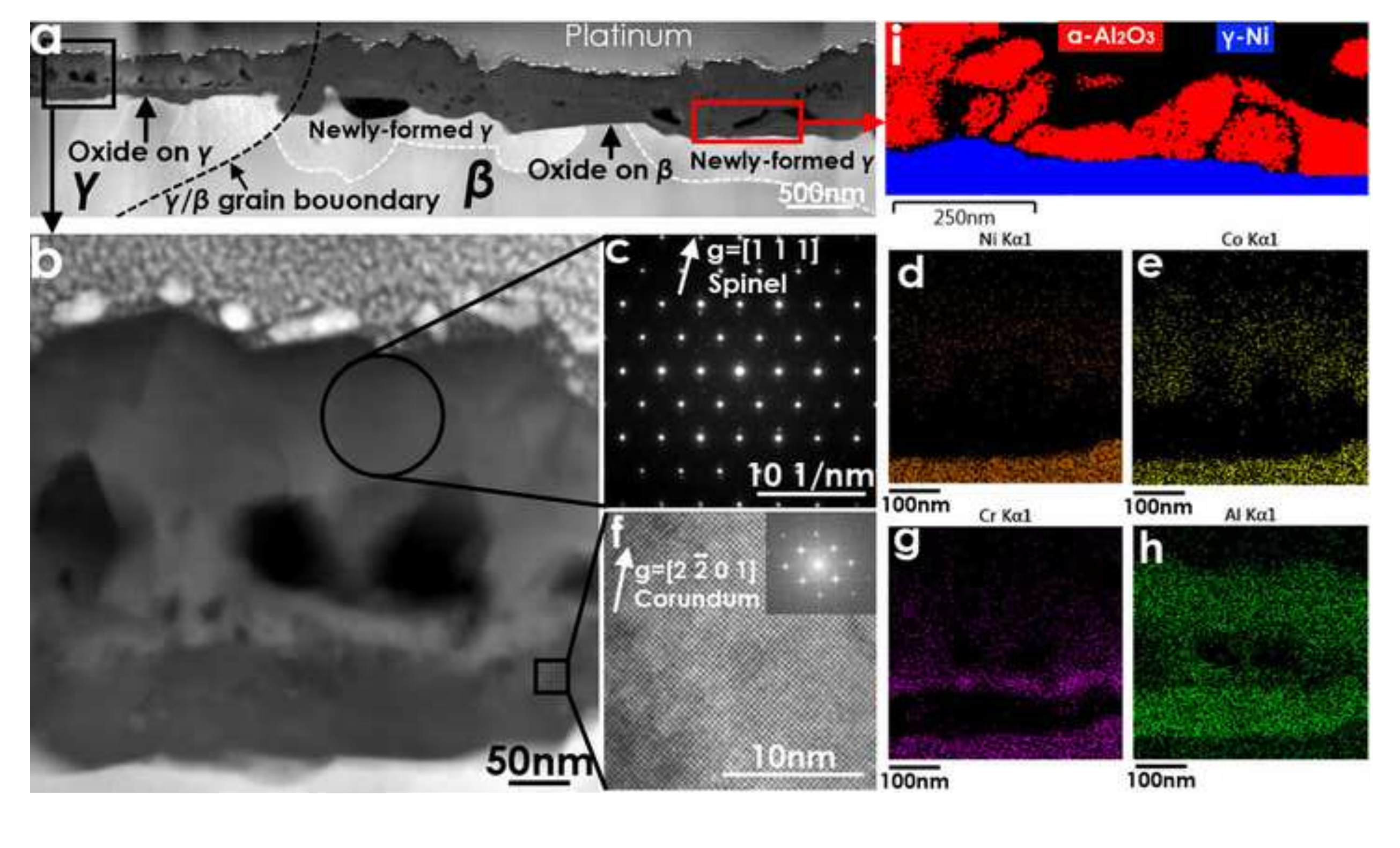

$\beta$ Oxide on $\beta$ Newly-formed $\gamma$

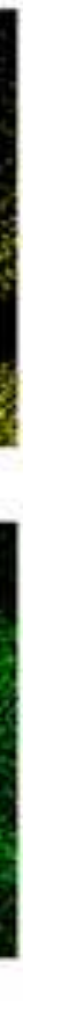

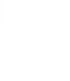




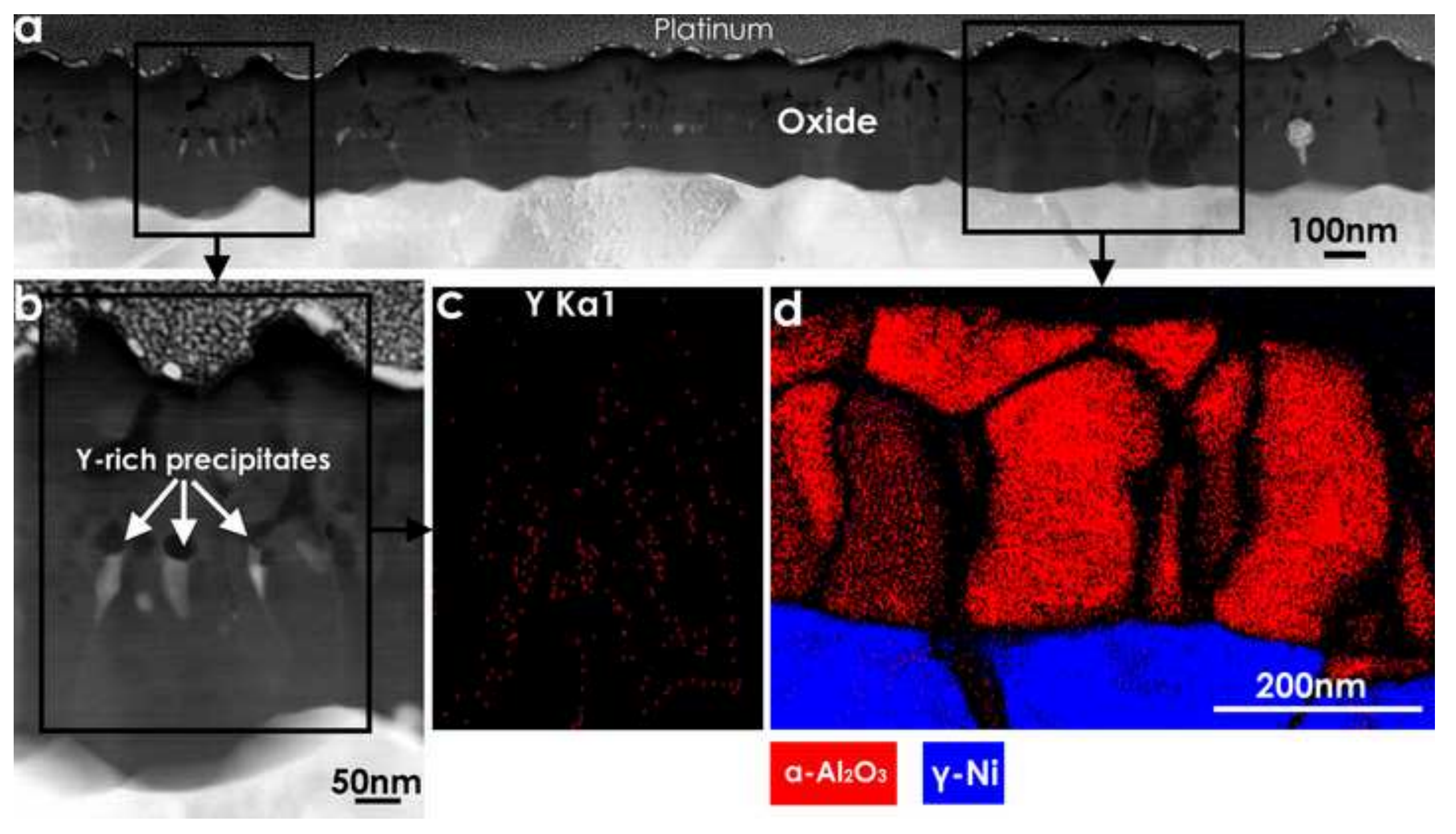

-
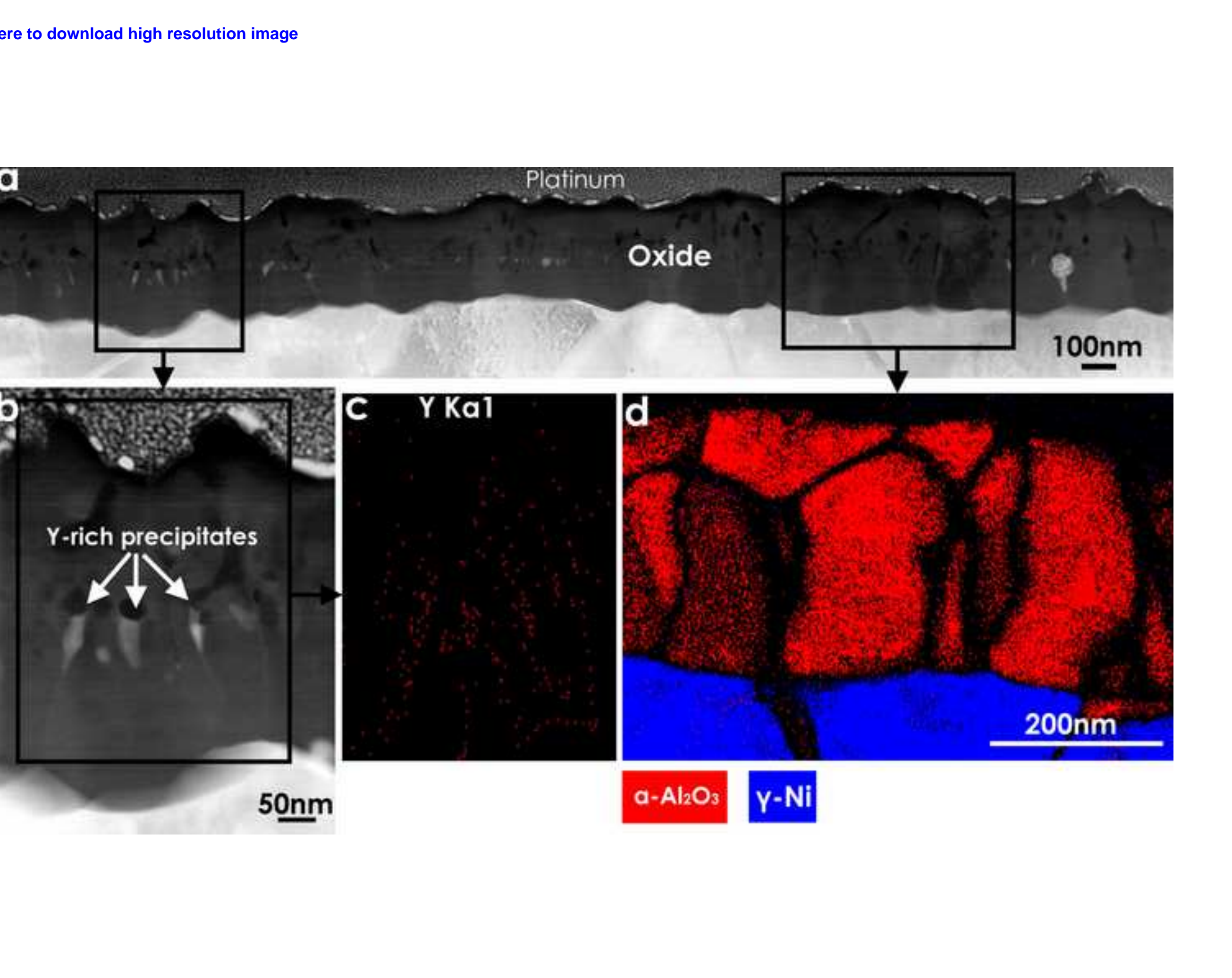

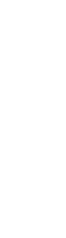
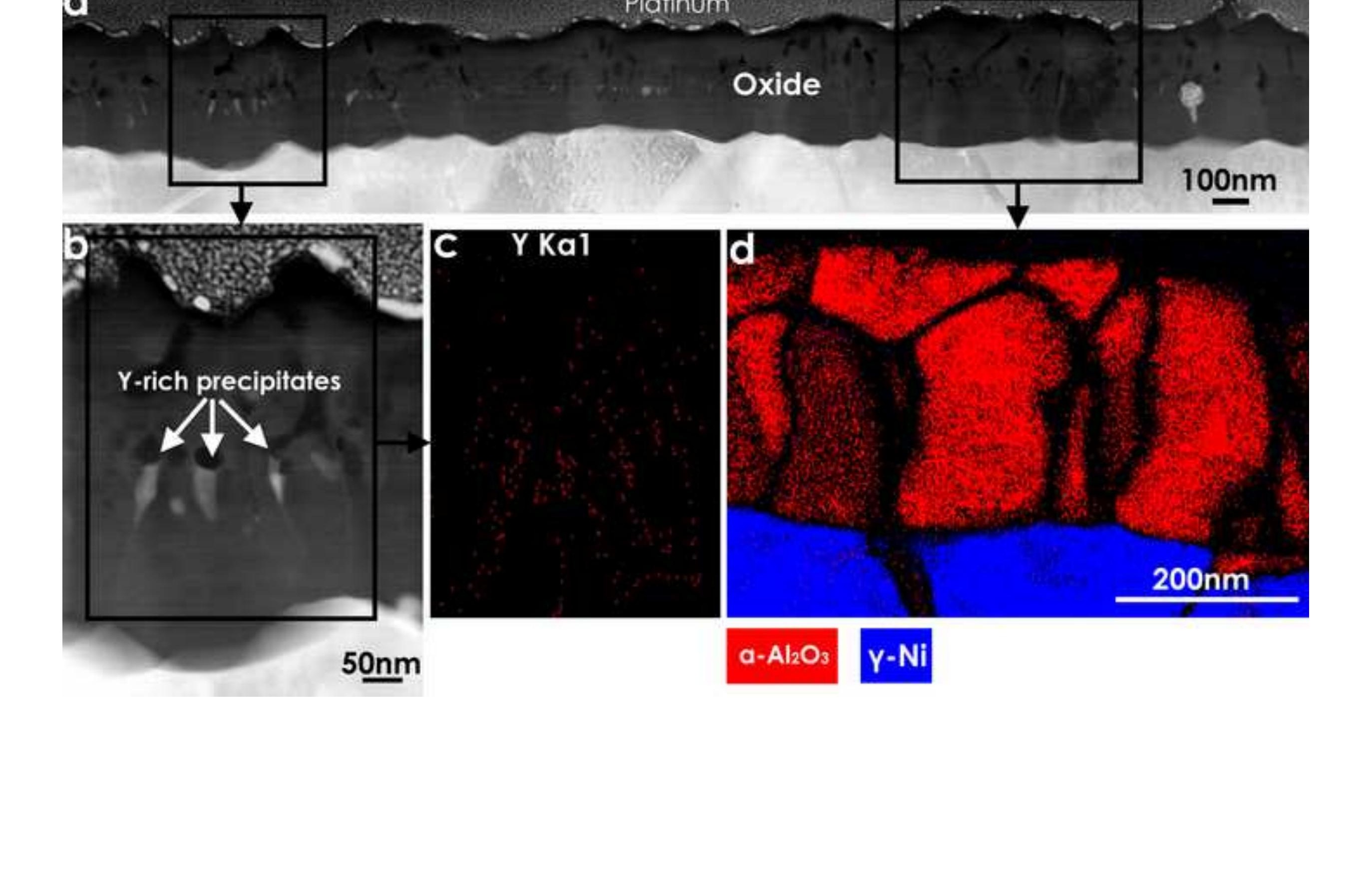
Click here to download high resolution image
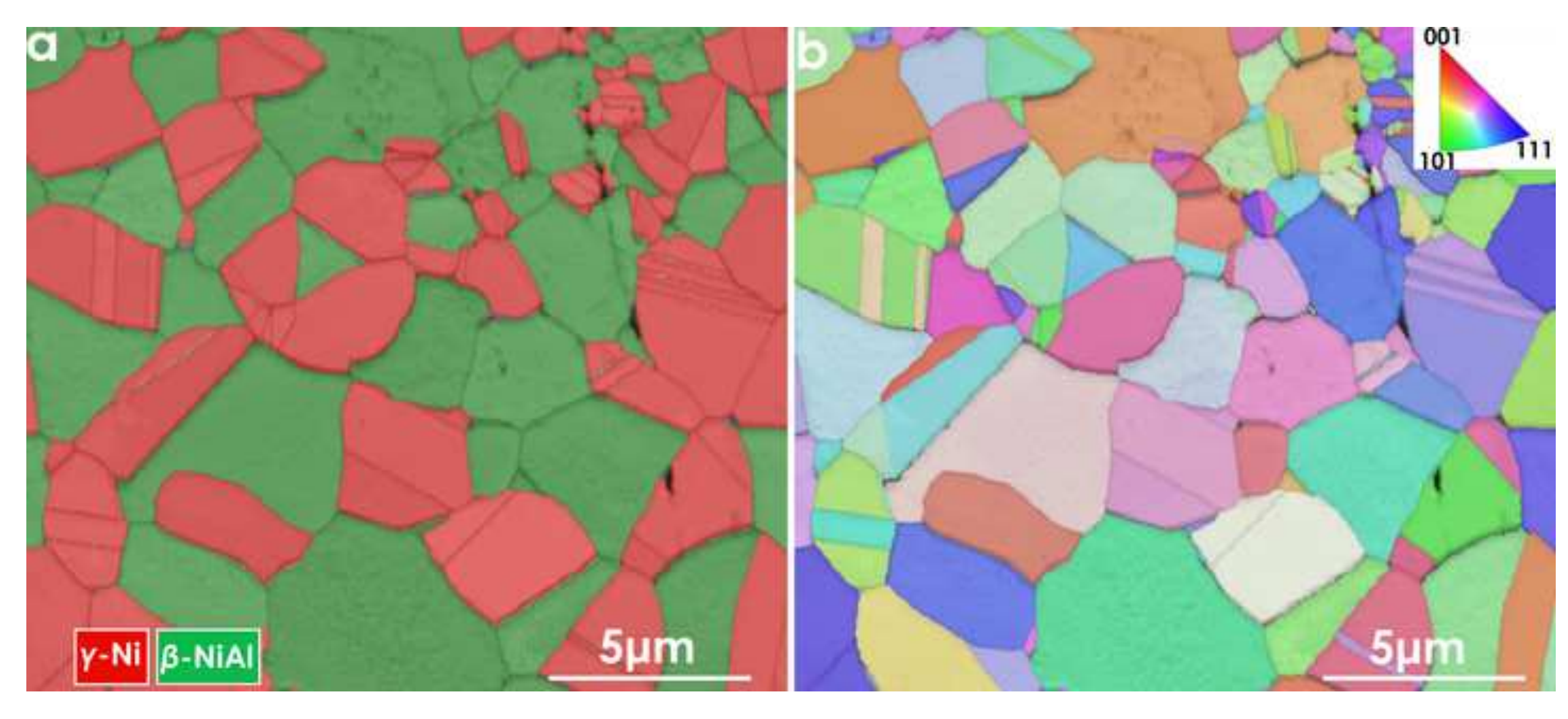

(a)

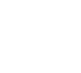

(1)




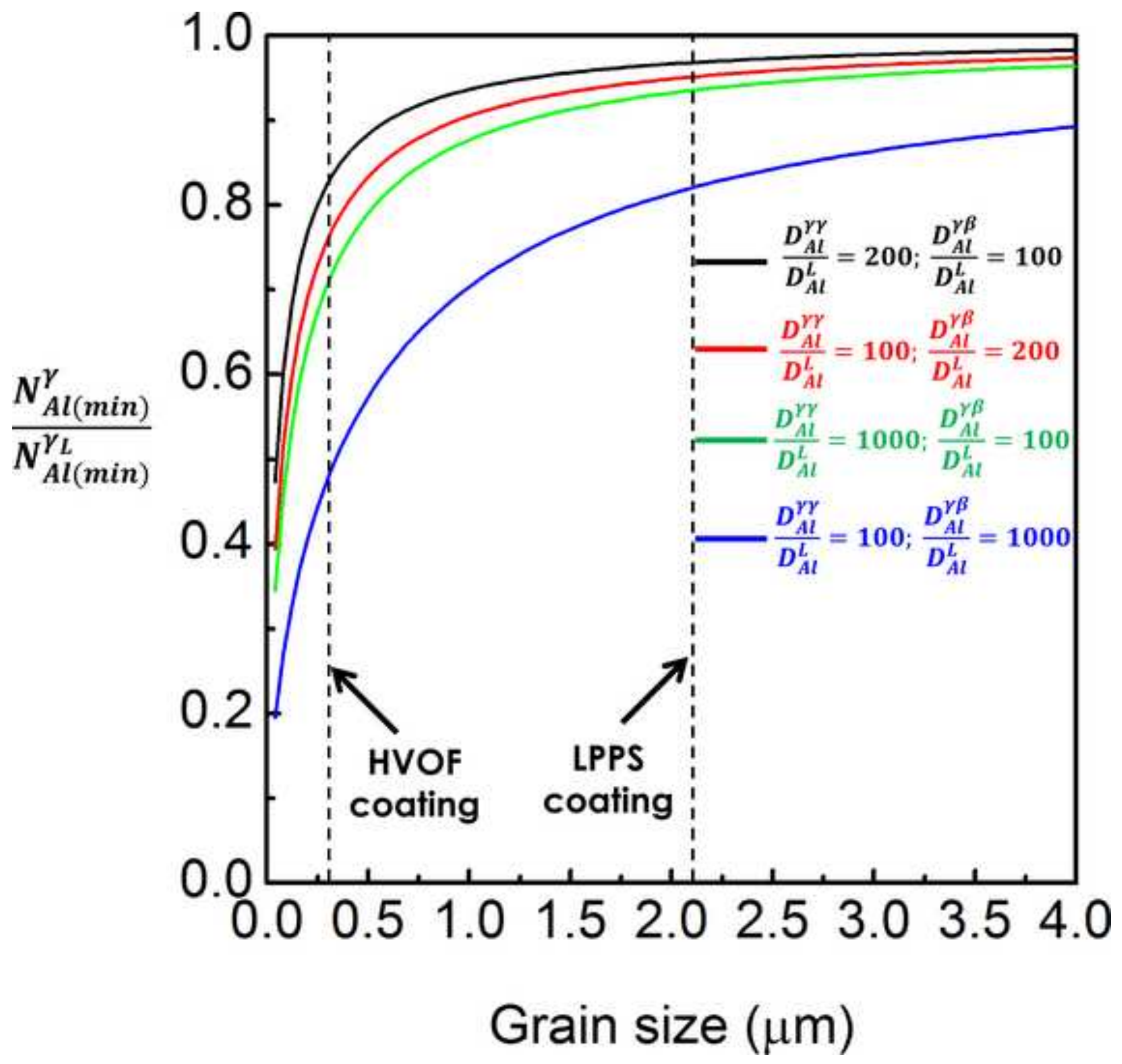




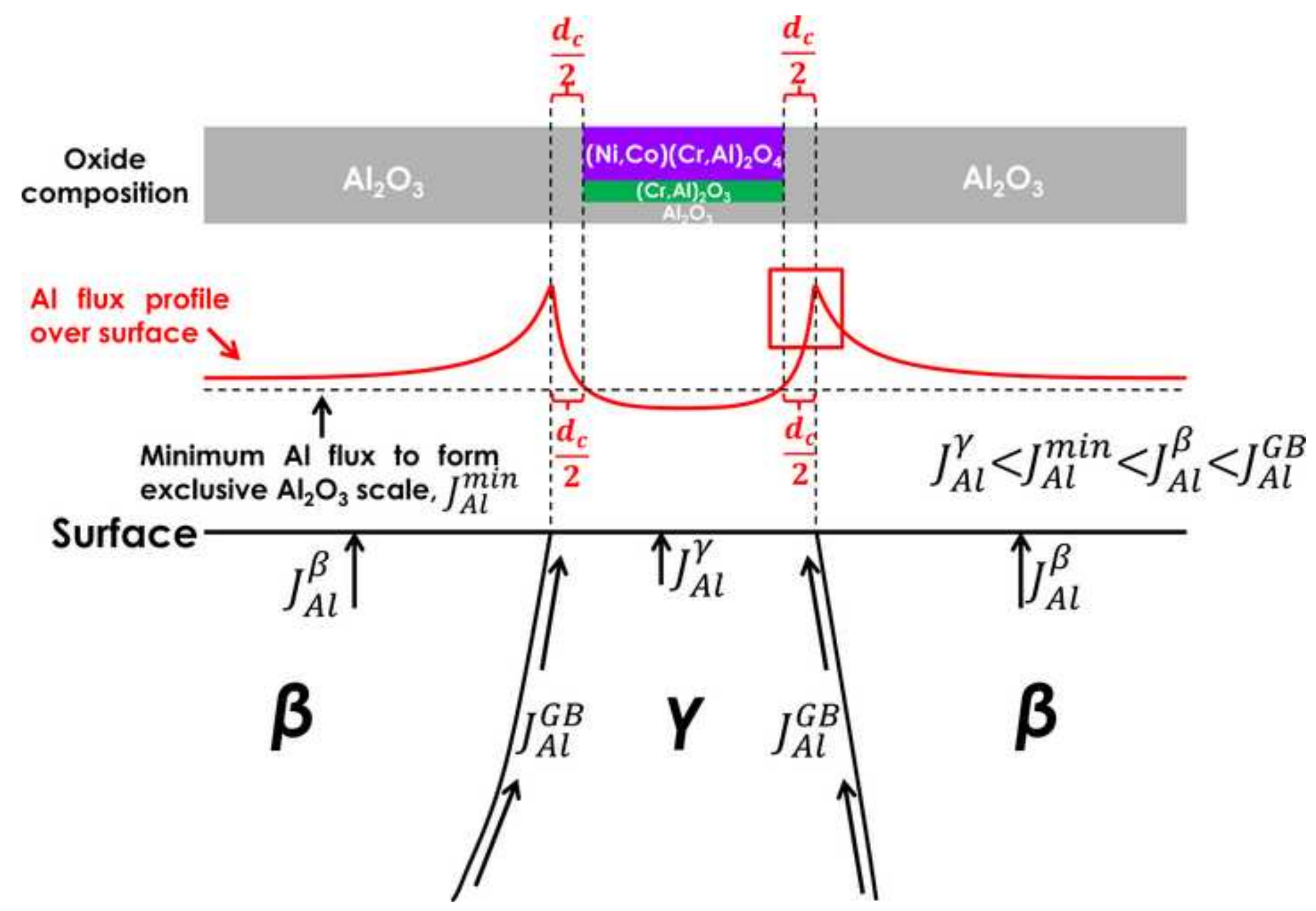




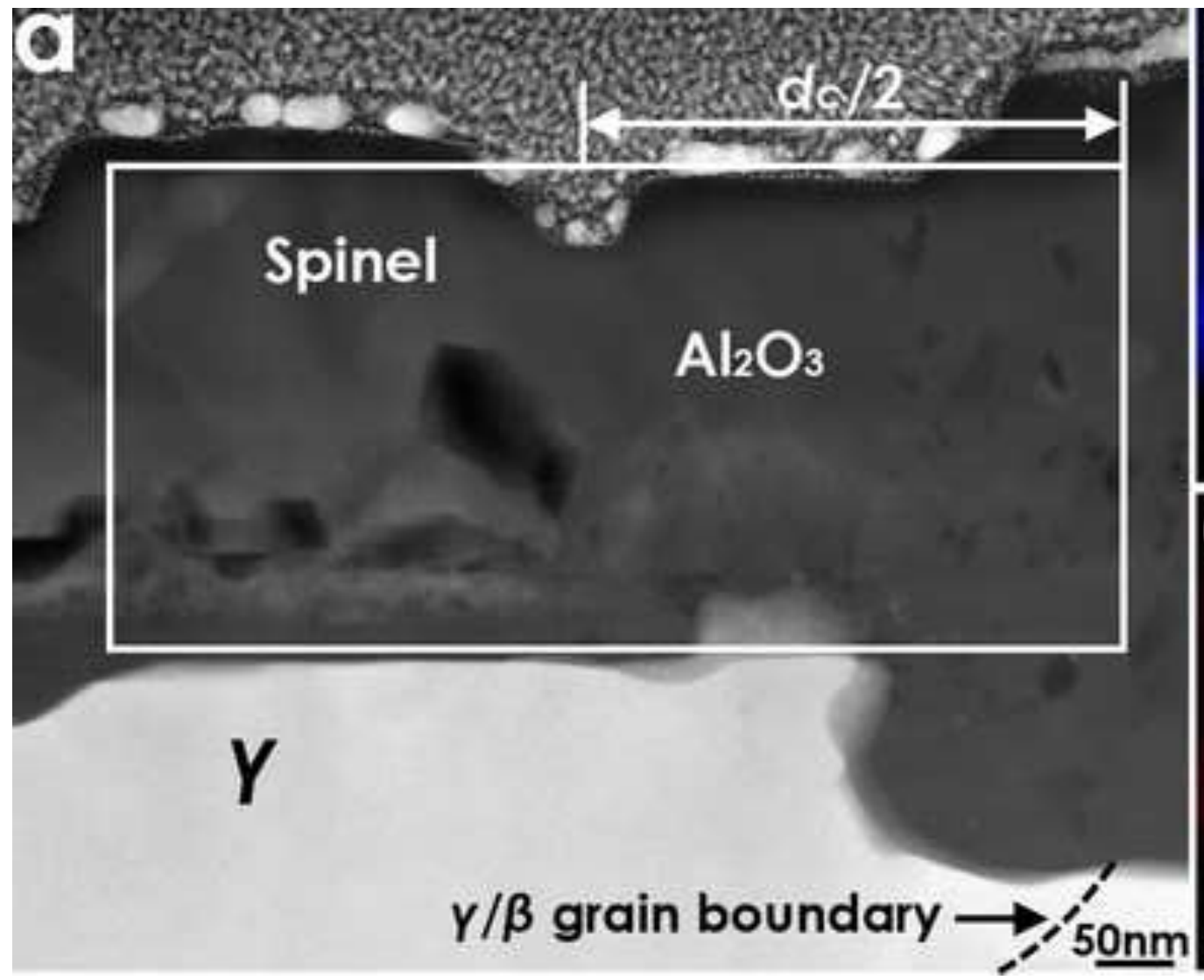

Co Ka1

$100 \mathrm{~nm}$

C

Ni Ka1

$100 \mathrm{~nm}$ 

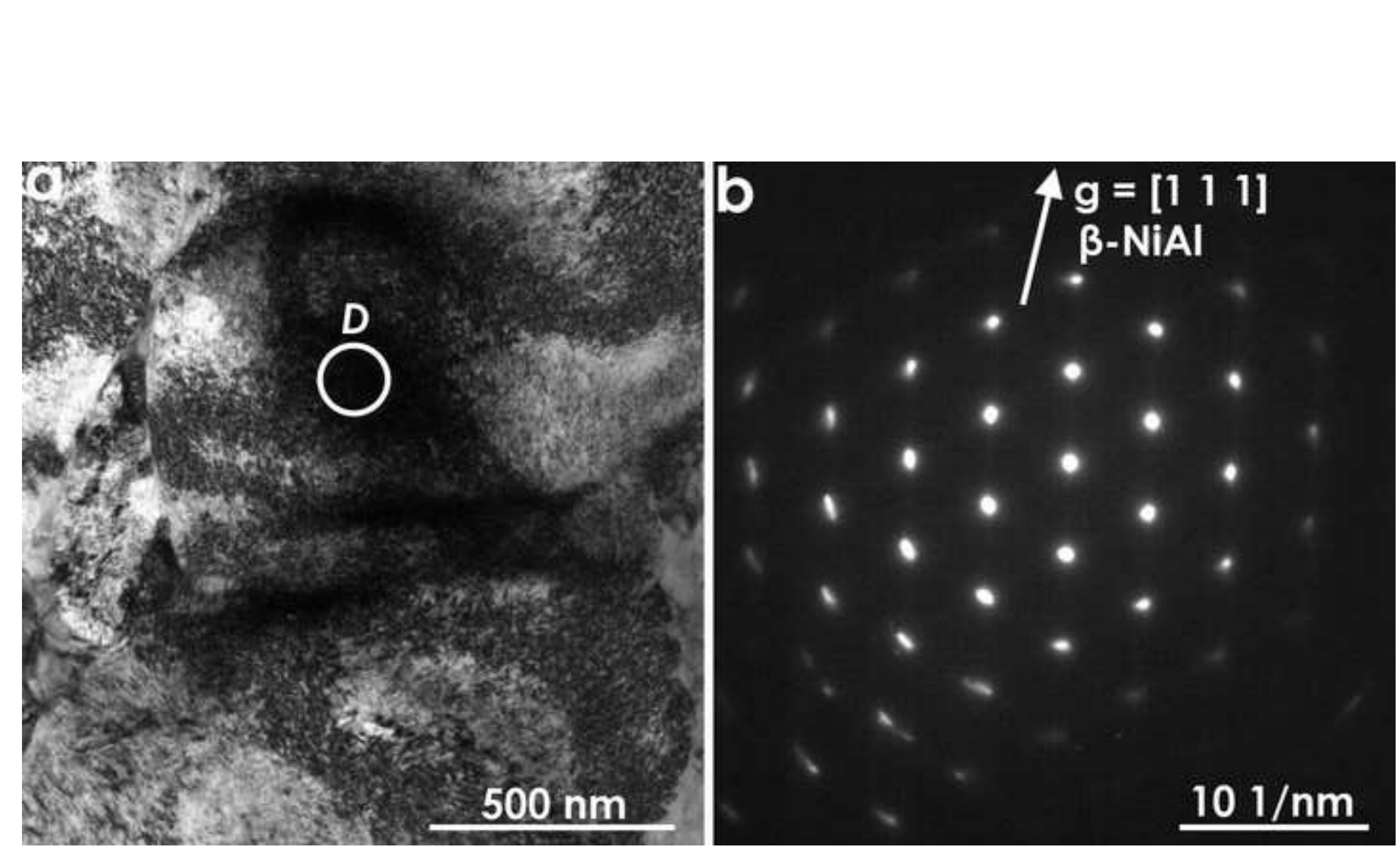
Click here to download high resolution image

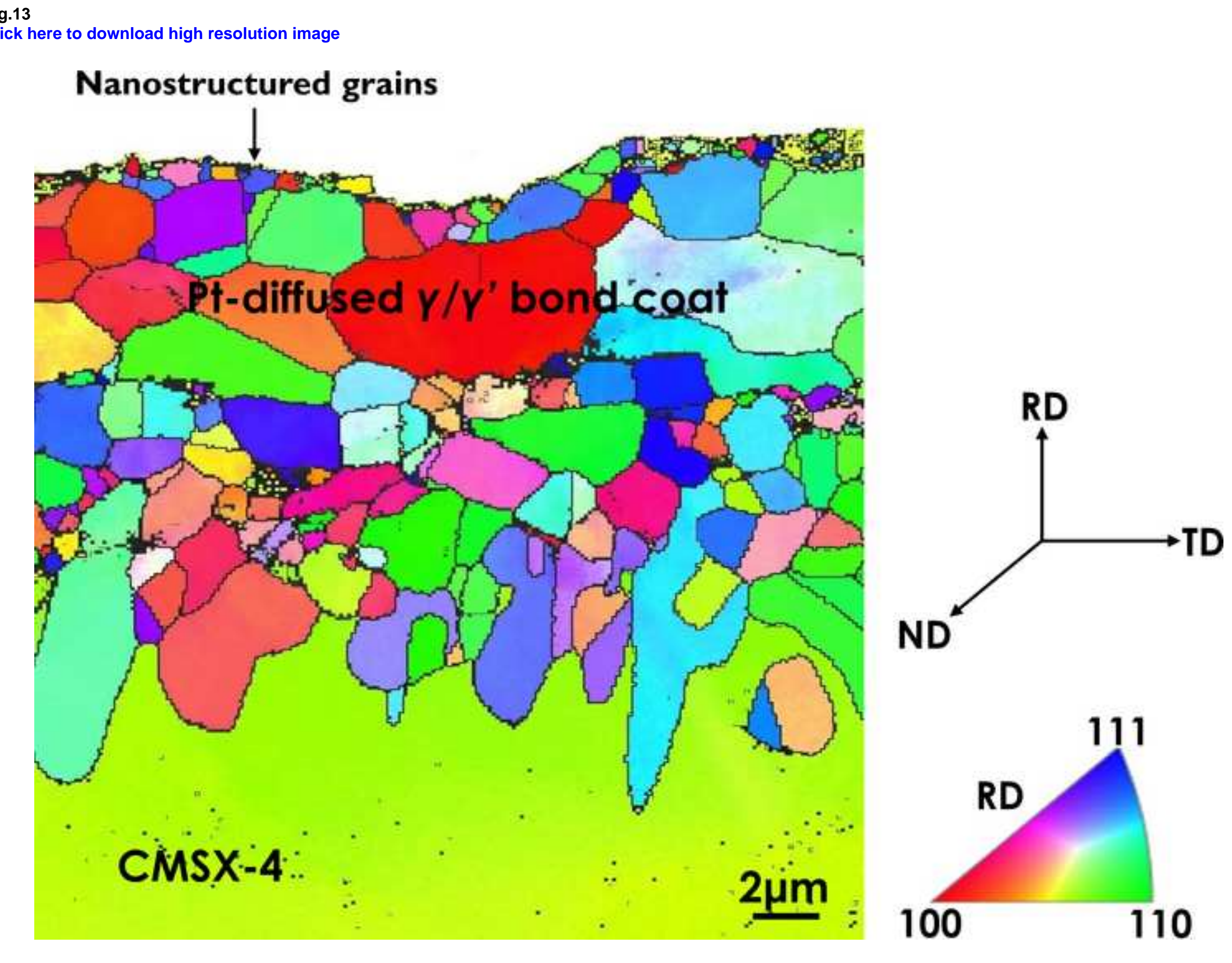

Nanostructured grains
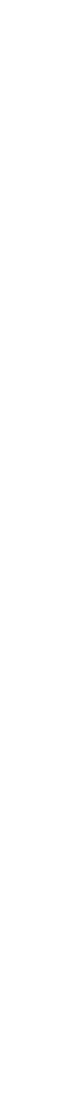

.


Table 1 Chemical compositions (wt. \%) of Hastelloy ${ }^{\circledR}$ X superalloy and MCrAlY coating

\begin{tabular}{ccccccccccccc}
\hline & $\mathrm{Ni}$ & $\mathrm{Cr}$ & $\mathrm{Co}$ & $\mathrm{Al}$ & $\mathrm{Y}$ & $\mathrm{Fe}$ & $\mathrm{Mo}$ & $\mathrm{W}$ & $\mathrm{C}$ & $\mathrm{Mn}$ & $\mathrm{Si}$ & $\mathrm{B}$ \\
\hline Hastelloy${ }^{\circledR} \mathrm{X}$ & Bal & 22 & 1.5 & $/$ & $/$ & 18 & 9 & 0.6 & 0.1 & $1^{*}$ & $1^{*}$ & $0.008^{*}$ \\
MCrAlY & Bal & 17 & 23 & 12.5 & 0.45 & $/$ & $/$ & $/$ & $/$ & $/$ & $/$ & $/$ \\
\hline
\end{tabular}

Table.2 Chemical compositions (at. \%) of the $\beta$ and $y$-phase determined by EDS point analysis

\begin{tabular}{ccccc}
\hline & $\mathrm{Ni}$ & $\mathrm{Co}$ & $\mathrm{Cr}$ & $\mathrm{Al}$ \\
\hline$\beta$ & 49.51 & 12.68 & 8.89 & 28.92 \\
$\gamma$ & 43.18 & 23.05 & 24.51 & 9.26 \\
\hline
\end{tabular}

Table $\underline{3} z$ Grain size and aspect ratio of $\beta$ and $y$-phase in LPPS and HVOF coatings

\begin{tabular}{ccccc}
\hline & \multicolumn{2}{c}{ LPPS coating } & \multicolumn{2}{c}{ HVOF coating } \\
\hline & Grain size $(\mu \mathrm{m})$ & Aspect ratio & Grain size $(\mu \mathrm{m})$ & Aspect ratio \\
$\beta$ & $2.68 \pm 1.12$ & $1.15 \pm 0.13$ & $0.78 \pm 0.31$ & $1.27 \pm 0.17$ \\
$Y$ & $2.11 \pm 0.85$ & $1.12 \pm 0.11$ & $0.31 \pm 0.19$ & $1-10$ \\
\hline
\end{tabular}

Table 43 Composition of the $Y$ and $Y^{\prime}$-phase in the surface region of a Ptdiffused $Y / Y^{\prime}$ bond coat [51]

\begin{tabular}{ccccccc}
\hline \multicolumn{7}{c}{ Main elements (at.\%) } \\
\hline & $\mathrm{Ni}$ & Al & Pt & Cr & Co & W \\
$Y$ & 61.8 & 8.2 & 11.8 & 9.3 & 7.4 & 1.0 \\
$Y^{\prime}$ & 50.3 & 22.5 & 23.5 & 0.9 & 2.6 & $/$ \\
\hline
\end{tabular}



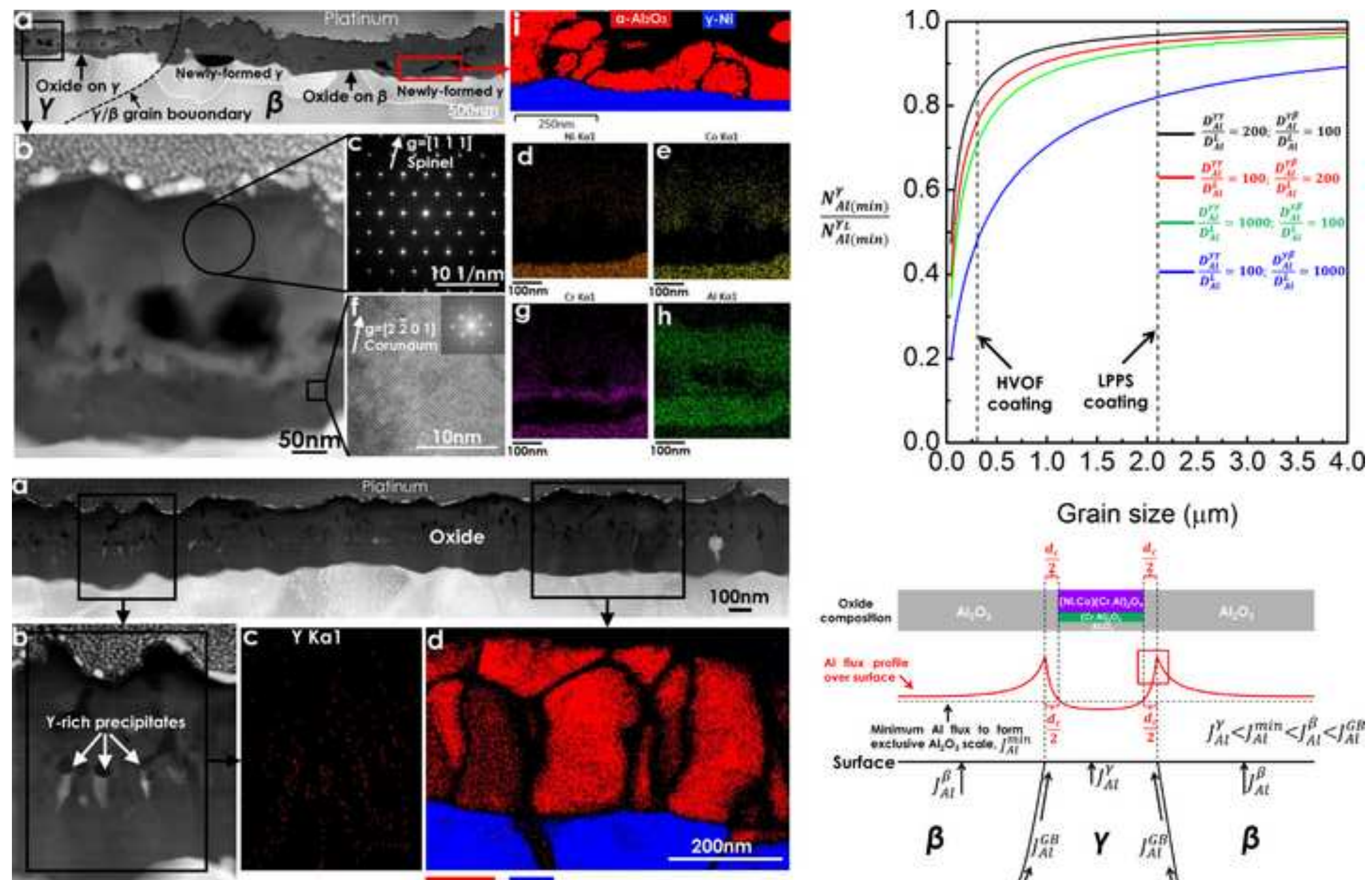

$50 \mathrm{~nm}$
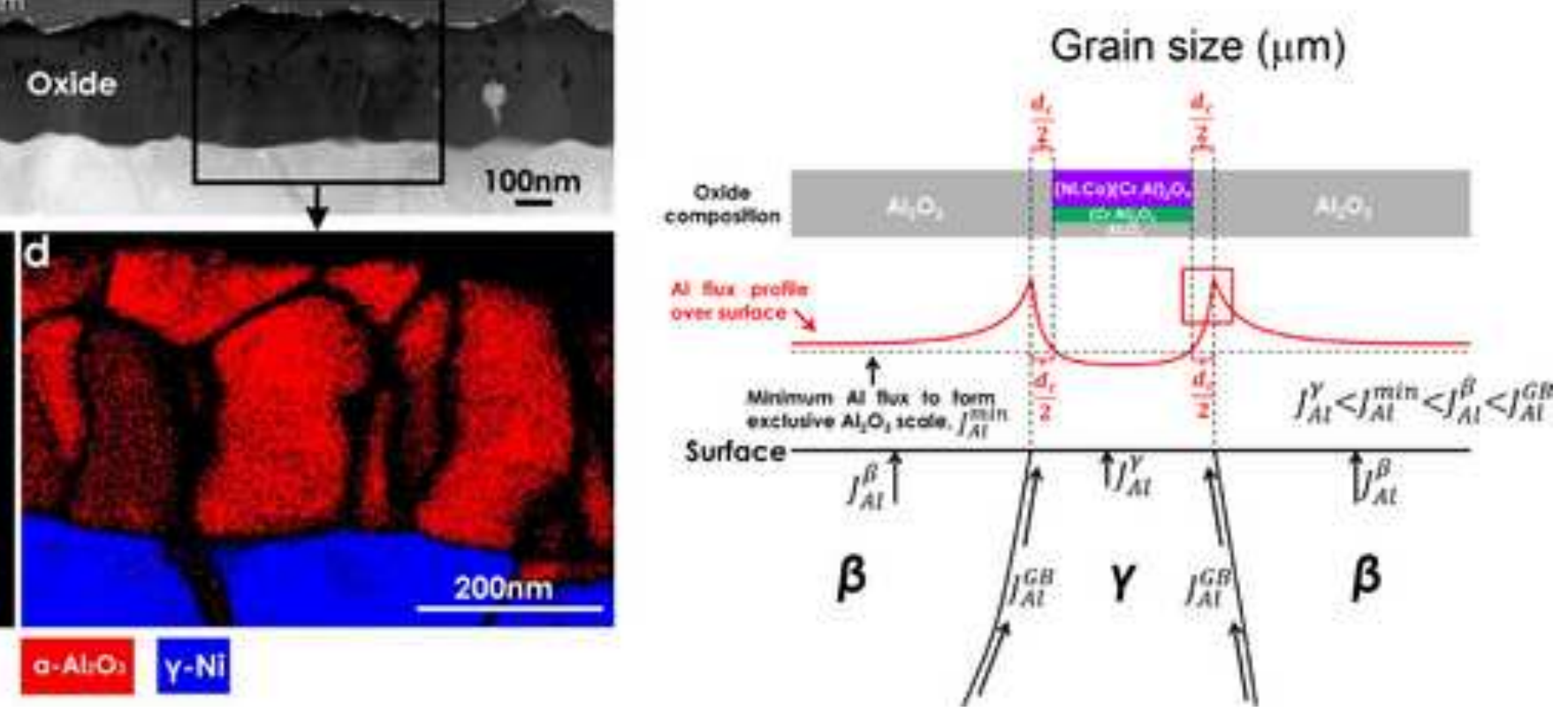